Article

\title{
8e Protects against Acute Cerebral Ischemia by Inhibition of PI3K $\gamma$-Mediated Superoxide Generation in Microglia
}

\author{
Linna Wang ${ }^{1,2}$, Xiaoli Wang ${ }^{3}$, Tingting $\mathrm{Li}^{1,2}$, Yihua Zhang ${ }^{4, *}$ and Hui $\mathrm{Ji}^{1,2, *}$ \\ 1 State Key Laboratory of Natural Medicines, China Pharmaceutical University, Nanjing 210009, \\ Jiangsu, China; aprilwln@stu.cpu.edu.cn (L.W.); 1ttcpu@cpu.edu.cn (T.L.) \\ 2 Department of Pharmacology, School of Pharmacy, China Pharmaceutical University, \\ Nanjing 210009, Jiangsu, China \\ 3 Key Laboratory of Carbohydrate Chemistry and Biotechnology, Ministry of Education, \\ School of Biotechnology, Jiangnan University, Wuxi 214122, Jiangsu, China; xiaoliwang@jiangnan.edu.cn \\ 4 Jiangsu Key Laboratory of Drug Discovery for Metabolic Diseases, China Pharmaceutical University, \\ Nanjing 210009, Jiangsu, China \\ * Correspondence: zyhtgd@163.com (Y.Z.); huiji@cpu.edu.cn (H.J.)
}

Received: 29 September 2018; Accepted: 29 October 2018; Published: 31 October 2018

check for updates

\begin{abstract}
The inflammatory response mediated by microglia plays a critical role in the progression of ischemic stroke. Phosphoinositide 3-kinase gamma (PI3K $\gamma$ ) has been implicated in multiple inflammatory and autoimmune diseases, making it a promising target for therapeutic intervention. The aim of this study was to evaluate the efficacy of $\mathbf{8 e}$, a hydrogen sulfide $\left(\mathrm{H}_{2} \mathrm{~S}\right)$ releasing derivative of 3- $n$-butylphthalide (NBP), on brain damage and PI3K $\gamma$ signaling following cerebral ischemia injury. 8e significantly reduced sensorimotor deficits, focal infarction, brain edema and neural apoptosis at $72 \mathrm{~h}$ after transient middle cerebral artery occlusion (tMCAO). The NOX2 isoform of the NADPH oxidase family is considered a major enzymatic source of superoxide. We found that the release of superoxide, together with the expression of NOX2 subunits $\mathrm{p} 47^{\mathrm{phox}}$, p-p47phox, and the upstream $\mathrm{PI} 3 \mathrm{~K} \gamma / \mathrm{AKT}$ signaling were all down-regulated by $\mathbf{8 e}$, both in the penumbral region of the rat brain and in the primary cultured microglia subjected to oxygen-glucose deprivation (OGD). With the use of siRNA and pharmacological inhibitors, we further demonstrated that $8 \mathbf{e}$ regulates the formation of superoxide in activated microglia through the PI3K $\gamma / \mathrm{AKT} / \mathrm{NOX} 2$ signaling pathway and subsequently prevents neuronal death in neighboring neurons. Our experimental data indicate that 8e is a potential candidate for the treatment of ischemic stroke and PI3K $\gamma$-mediated neuroinflammation.
\end{abstract}

Keywords: hydrogen sulfide; cerebral ischemia/reperfusion; microglial activation; NOX2; PI3K $\gamma$

\section{Introduction}

As one of the major causes of death and serious long-term disability, stroke produces immense health and economic burdens globally. In 2013, 6.5 million stroke deaths were reported worldwide, $67 \%$ of which were caused by ischemic stroke [1]. Intravenous thrombolysis with tissue-type plasminogen activator (tPA) is the only approved treatment for acute ischemic stroke, but the benefit is strongly time-dependent. Although the therapeutic window of tPA safely extends to three to four and a half hours after the onset of stroke symptoms [2,3], it is not sufficient for patients to receive timely thrombolytic therapy.

A tremendous amount of work has been done on developing neuroprotective agents, which appeared to be quite credible on animal models. However, none of these agents have been demonstrated to be effective where humans are concerned. This may be partly due to overlooking the fact that all cell types 
in the brain, not only neurons, respond to ischemic brain injury [4]. Homeostatic signaling among cell types maintains normal brain function, while disordered signaling contributes to the progression of injury after stroke [5]. Emerging evidence from recent studies now suggests that therapeutic approaches should target multiple cell types to protect their structural and functional integrity as well as interactions, especially in the salvageable penumbral region [5,6]. Intricate mechanisms are triggered within the penumbra following the onset of cerebral ischemia/reperfusion, and prominent inflammatory response is believed to play a critical role in exacerbating post-ischemic injury, especially neural damage $[7,8]$. As the major resident immune cells in the brain, microglia change from surveying to activated states when the neuronal death expands in the ischemic core and spreads to the penumbra, which affects the fate of microglia and their neighboring neurons $[9,10]$. Despite a poor reputation, the activation of microglia is now considered to be a protective response; however, one which the impaired central nervous system (CNS) can barely tolerate and which is therefore destructive [11,12]. From this perspective, we should search for novel treatments which can appropriately regulate the activation of microglia, to save vulnerable neurons from ischemic injury [11].

Activated microglia generate excessive amounts of reactive oxygen species (ROS), and ROS in turn promote microglial proliferation in a feed-forward manner $[13,14]$. Stimulation of NADPH oxidase activity is the predominant mechanism involved in ROS production following cerebral ischemia [15]. Although nearly all cell types in the brain express one or more NADPH oxidase (NOX) isoforms, microglia express the highest levels of NOX, especially NOX2 [16]. NOX2 is composed of membrane subunits (p22 phox and gp91 ${ }^{\text {phox }}$ ) and cytosolic subunits (p47phox, p67phox, and p40phox). Phosphorylation of $4^{4} 7^{\text {phox }}$ induces its association with $\mathrm{p}^{22^{\text {phox }}}$ and translocation to cell membranes, which in turn promotes interaction with p67phox and the small GTPase Rac to form an active enzyme complex [17]. It has been suggested that AKT triggers the phosphorylation of p47phox in leukocytes

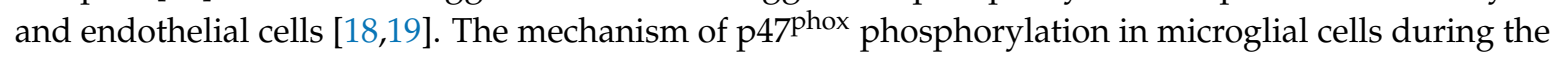
process of stroke is not yet fully understood.

Phosphoinositide 3-kinases (PI3Ks) regulate several key functions of immune cells ranging from development, proliferation to migration and cytokine production [20]. A substantial amount of data indicate that the Class IB isoform-PI3K $\gamma$ is correlated with many inflammatory and autoimmune diseases, making it a promising target for therapeutic intervention. Numerous efforts have focused on the compelling effects of phosphoinositide 3-kinase gamma (PI3K $\gamma$ ) in systemic inflammation [21-23], but less attention is paid to its contribution to CNS inflammatory response in spite of the high abundance in the brain [24]. It has been shown that genetic and pharmacological inhibition of PI3K $\gamma$ prevented Alzheimer's disease and surgical brain injury $[25,26]$. However, there is still debate about the role of $\mathrm{PI} 3 \mathrm{~K} \gamma$ during stroke because although genetic deletion of $\mathrm{PI} 3 \mathrm{~K} \gamma$ reduced cerebral ischemic injury in some studies [27,28], it worsened the brain damage in others [29]. Moreover, the cellular location of PI3K $\gamma$ in the CNS is also controversial $[27,30]$. Therefore, further investigation of the role of $\mathrm{PI} 3 \mathrm{~K} \gamma$ signaling in neuroinflammation is urgently needed.

Hydrogen sulfide $\left(\mathrm{H}_{2} \mathrm{~S}\right)$ is well known as the third gasotransmitter beside nitric oxide (NO) and carbon monoxide (CO) [31]. Many researchers have found that exogenous $\mathrm{H}_{2} \mathrm{~S}$ could attenuate ischemic injury in various organs and tissues, including the heart, liver and kidney [32-34]. The protective effects of $\mathrm{H}_{2} \mathrm{~S}$-releasing compounds, especially the ones with $\mathrm{H}_{2} \mathrm{~S}$ slow-releasing donors, in cerebral ischemia is also discussed [35], but the underlying mechanism has not been thoroughly investigated. Our previous work has demonstrated that 8e (Figure 1), an NBP-derivative combined with $\mathrm{H}_{2} \mathrm{~S}$ donor ADT-OH (5-(4-hydroxyphenyl)-3H-1,2-dithiole-3-thione), exhibiting antiplatelet and antithrombotic activities, was a potential agent for the treatment of ischemic stroke [36]. Recent reports by one group showed that ADT-OH suppressed inflammatory response in microglial cells [37] and ADT conferred neuroprotection through regulating NOX4-derived ROS [38]. At the same time, several reports also showed that $\mathrm{H}_{2} \mathrm{~S}$ donor exerts neuroprotection through anti-inflammatory effects in microglia [39-41] and anti-oxidative effects via NADPH oxidases [42-44]. We hypothesize that the essential mechanisms of $\mathrm{H}_{2} \mathrm{~S}$ and 8e during stroke are involved with microglial activation following oxidative stress. 


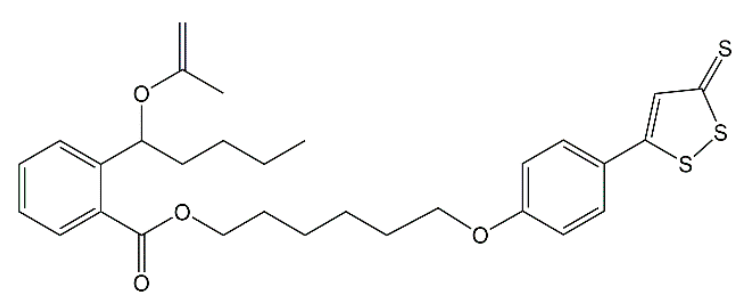

Figure 1. Chemical structure of $8 \mathbf{e}$.

In the present study, we assessed the therapeutic effects of $\mathbf{8 e}$ by studying the sensorimotor dysfunction and brain injury in a rat model of focal ischemic stroke induced by transient middle cerebral artery occlusion (tMCAO). Further investigation into the involvement of NOX2-derived superoxide and PI $3 \mathrm{~K} \gamma$ signaling in the protective mechanism of $8 \mathbf{e}$ was conducted. To replicate the condition of microglia and the interaction of neuron-microglia after stroke, primary microglia cultures were exposed to oxygen-glucose deprivation (OGD). 8e down-regulated the PI3K $\gamma / \mathrm{AKT} / \mathrm{NOX} 2$ pathway in microglial cells and subsequently attenuated neuronal death in vitro. Our results indicate that $\mathbf{8} \mathbf{e}$ is a promising candidate for the treatment of ischemic stroke.

\section{Results}

\subsection{8e Enhanced Sensorimotor Function after Cerebral I/R in Rats}

Middle cerebral artery occlusion (MCAO) in rats induces lesions in the cortical and striatal regions which are involved in the processing of sensorimotor information. Impairment of behavior may reflect changes in brain function. A series of behavioral assessments was conducted to determine the neurological and sensorimotor deficits at $24 \mathrm{~h}, 48 \mathrm{~h}$ and $72 \mathrm{~h}$ following transient middle cerebral artery occlusion (tMCAO). In the Longa test, which offers a graded scale of body movement post ischemic injury, a repeated measures ANOVA showed a significant group effect $(\mathrm{F}=41.88, p<0.0001)$, but no time or interaction effect $(\mathrm{F}=2.823, p=0.061 ; \mathrm{F}=0.810, p=0.620)$. Rats in the tMCAO + vehicle group showed severe neurological impairment at every time point tested $(p<0.001$, respectively; Figure $2 \mathrm{~A}-\mathrm{C})$. Trends of functional improvement were observed in the 8e treatment groups, while significant differences were only found between $20 \mathrm{mg} / \mathrm{kg} 8 \mathbf{e}$ and $\mathrm{tMCAO}+$ vehicle group at $48 \mathrm{~h}$ after tMCAO $(p<0.05)$.

A significant group effect $(\mathrm{F}=33.36, p<0.0001)$ in the beam walking test, which reflects motor coordination, was observed without time or interaction effect $(\mathrm{F}=0.282, p=0.755 ; \mathrm{F}=0.374, p=0.957)$. Post hoc analyses showed that beam walking ability was remarkably impaired in vehicle-treated animals for three days after tMCAO ( $p<0.001$, respectively; Figure 2D-F). The foot slip ratios were notably decreased in rats treated with $10 \mathrm{mg} / \mathrm{kg}$ and $20 \mathrm{mg} / \mathrm{kg} 8 \mathbf{e}$ at $48 \mathrm{~h}(p<0.05$, respectively) and $72 \mathrm{~h}$ after tMCAO $(p<0.01$, respectively). AS252424, a PI3K $\gamma$ pharmacological inhibitor, also reduced foot slip ratios and showed statistical differences in the beam walking test.

The prehensile traction test primarily measures impaired forelimb placement and muscle strength by the length of time spent on the rope. A significant group effect $(\mathrm{F}=49.25, p<0.0001)$ but no time or interaction effect $(\mathrm{F}=0.509, p=0.602 ; \mathrm{F}=0.473, p=0.907)$ was found. At $24 \mathrm{~h}, 48 \mathrm{~h}$ and $72 \mathrm{~h}$ after tMCAO, the vehicle-treated rats spent shorter lengths of time on the rope $(p<0.001$, respectively; Figure 2G-I). 8e at a dose of $20 \mathrm{mg} / \mathrm{kg}$ profoundly increased muscle strength at $48 \mathrm{~h}$ and $72 \mathrm{~h}$ after $\operatorname{tMCAO}(p<0.05, p<0.001$, respectively). Similar results were obtained after 8e treatment of $10 \mathrm{mg} / \mathrm{kg}$ at the same two time points ( $p<0.01$, respectively). These findings suggested that $8 \mathbf{e}$ could improve behavioral outcomes after tMCAO through three days of treatment. 
A

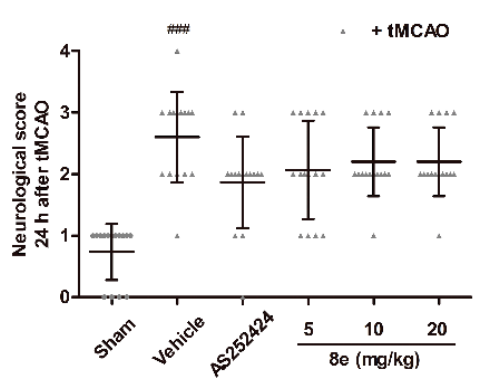

D

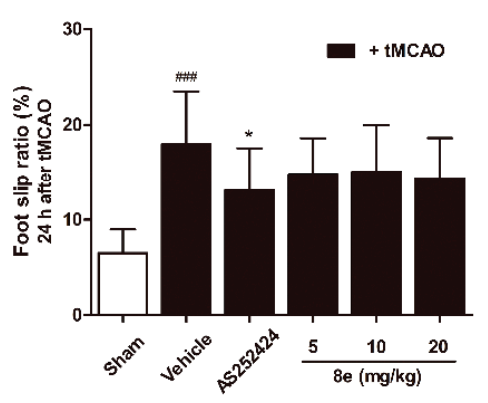

G

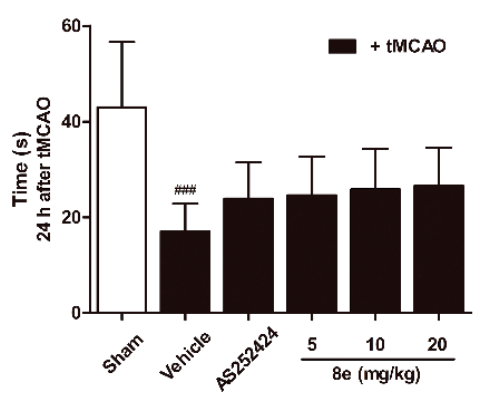

B

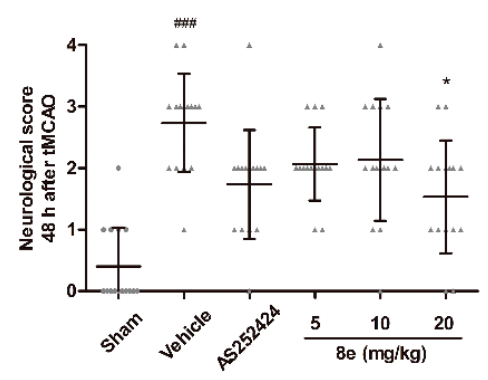

$\mathbf{E}$

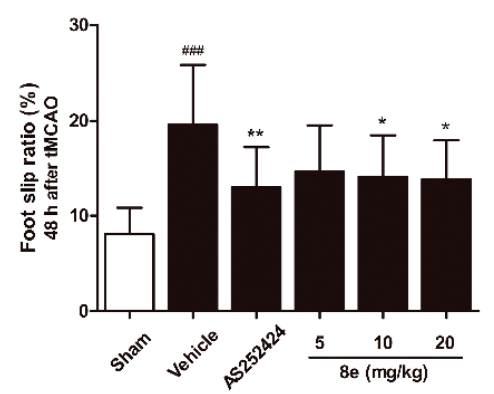

H

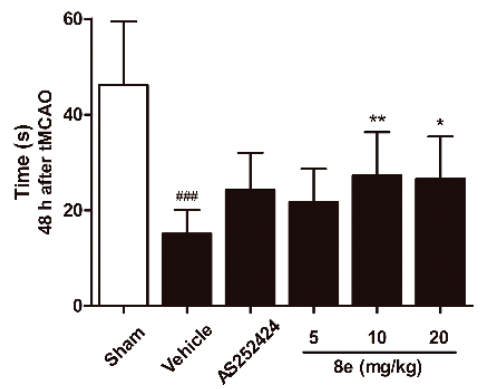

C

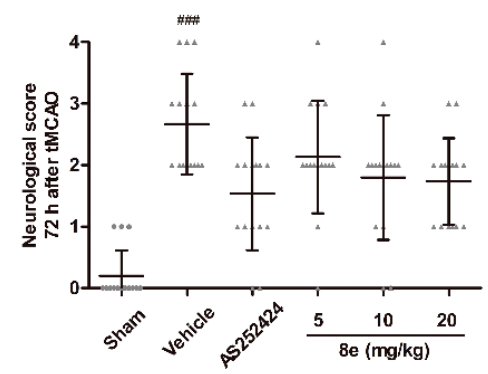

$\mathbf{F}$

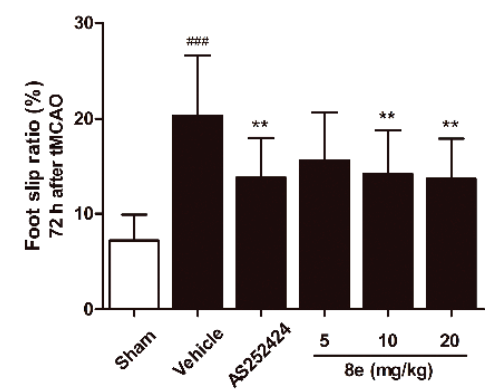

I

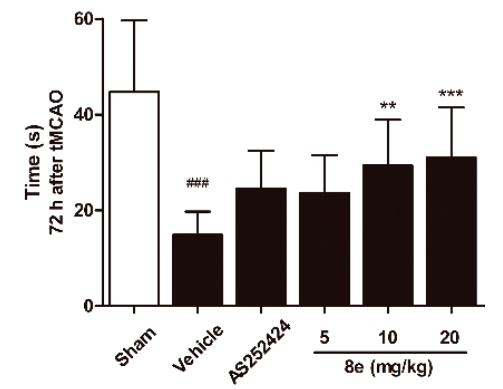

Figure 2. 8e enhanced sensorimotor function after cerebral ischemia/reperfusion (I/R) in rats. (A-C) Neurological scores in Longa test; (D-F) foot slip ratios in beam walking test; (G-I) time spent on the rope in prehensile traction test at $24 \mathrm{~h}, 48 \mathrm{~h}$ and $72 \mathrm{~h}$ after transient middle cerebral artery occlusion (tMCAO). Data are presented as mean $\pm \mathrm{SD}(n=15)$. ${ }^{\# \#} p<0.001$ vs. sham group. ${ }^{*} p<0.05$, ${ }^{* *} p<0.01{ }^{* * *} p<0.001$ vs. tMCAO + vehicle group.

2.2. 8e Exerted Protective Effect against Cerebral I/R Injury, Histological Damage and Neural Apoptosis in Rats

Brain infarct volume after tMCAO was tested by TTC staining to quantify morphological changes (Figure 3A,B). The infarctions declined in rats treated with 8 e at $10 \mathrm{mg} / \mathrm{kg}(p<0.05)$ and $20 \mathrm{mg} / \mathrm{kg}$ $(p<0.01)$ compared with the tMCAO + vehicle group. At $72 \mathrm{~h}$ after reperfusion, water contents were increased in the ipsilateral hemispheres of the vehicle group $(p<0.05$, Figure 3C). All 8e treatment decreased brain edema, but statistical significance was found only in the $20 \mathrm{mg} / \mathrm{kg}$ group $(p<0.05)$. 
A

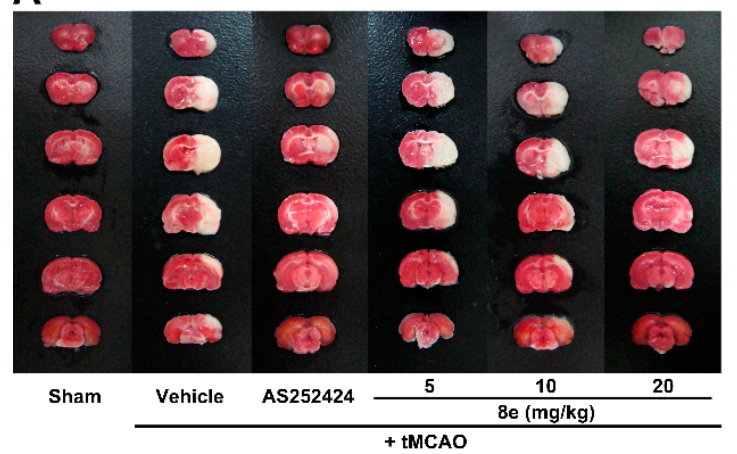

B

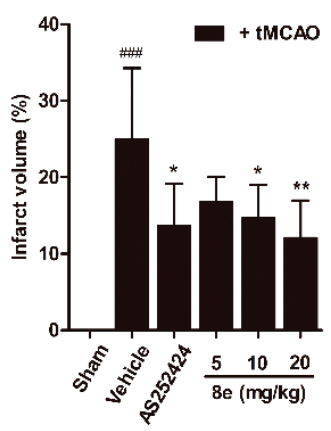

C

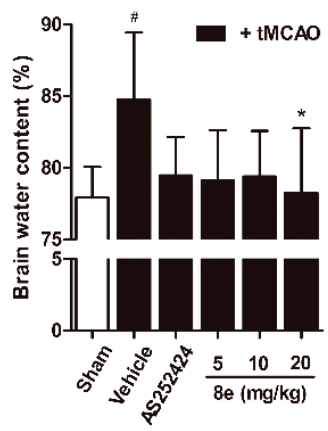

D

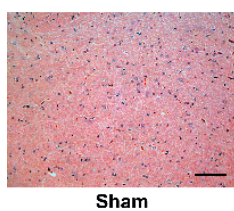

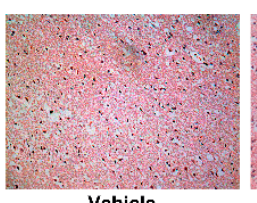

Vehicle

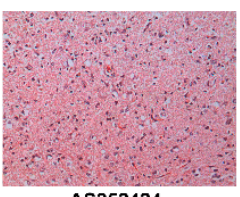

AS252424

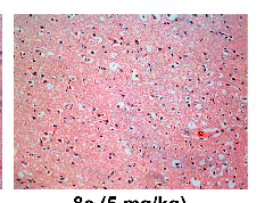

$8 \mathrm{e}(5 \mathrm{mg} / \mathrm{kg})$

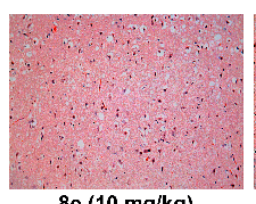

$8 \mathrm{e}(10 \mathrm{mg} / \mathrm{kg})$

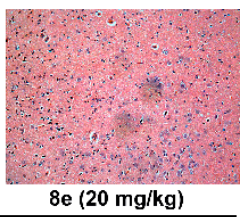

$8 \mathrm{e}(20 \mathrm{mg} / \mathrm{kg})$

E
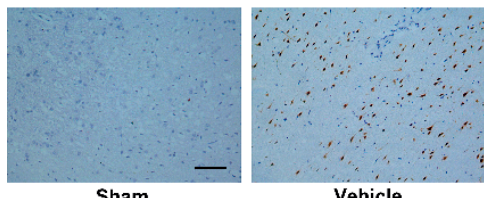

Vehicle

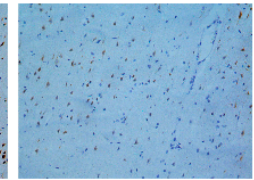

AS252424

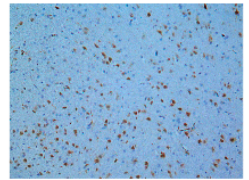

$8 \mathrm{e}(5 \mathrm{mg} / \mathrm{kg})$ + tMCAO

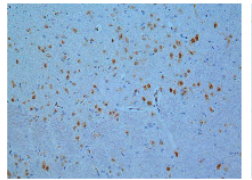

$8 \mathrm{e}(10 \mathrm{mg} / \mathrm{kg})$

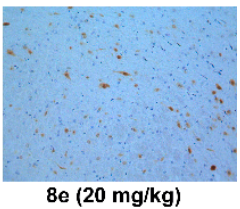

$\mathbf{F}$

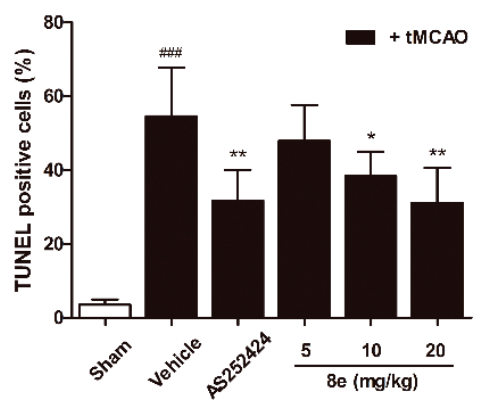

Figure 3. 8e protected against cerebral I/R injury, histological damage and neural apoptosis at $72 \mathrm{~h}$ after tMCAO in rats. (A) Representative images of TTC staining on rat brain sections; (B) quantitative analysis of infarct volumes in TTC staining $(n=6)$; (C) brain water contents in ipsilateral hemispheres $(n=6)$; (D) representative images of H\&E staining; (E) TUNEL staining at $200 \times$ magnification. Scale bar $=100 \mu \mathrm{m} ;(\mathbf{F})$ quantitative analysis of the percentage ratios of TUNEL positive cells $(n$ =3). Data are presented as mean \pm SD. ${ }^{\#} p<0.05,{ }^{\# \#} p<0.001$ vs. sham group. ${ }^{*} p<0.05,{ }^{* *} p<0.01$ vs. tMCAO + vehicle group.

As shown in Figure 3D, tMCAO surgery induced severe histological damage in rats treated with a vehicle based on hematoxylin and eosin (H\&E) staining. The presence of all three doses of $\mathbf{8 e}$ notably reduced the numbers of pyknotic nuclei and vacuolization. TUNEL staining was performed to investigate whether 8e could affect neural apoptosis following I/R (Figure 3E). The results showed that the numbers of TUNEL positive nuclei, i.e., the apoptotic nuclei, in the 8e-treated groups were much fewer than those in the tMCAO + vehicle group $(10 \mathrm{mg} / \mathrm{kg}, p<0.05 ; 20 \mathrm{mg} / \mathrm{kg}, p<0.01)$. Similarly, PI3K $\gamma$-selective inhibitor AS252424 also exhibited marked protection against I/R injury, proving that inhibition of $\mathrm{PI} 3 \mathrm{~K} \gamma$ is a potential approach to treat cerebral ischemia. 


\subsection{8e Attenuated Superoxide Production Following Cerebral I/R in Rats}

ROS are critical mediators in the pathology of acute ischemic stroke. Superoxide is one of the most important ROS which can directly cause oxidative damage to nearby neural cells or can interact with other molecules to generate "secondary" radicals [45]. The effect of $\mathbf{8 e}$ on superoxide production was evaluated with the DHE staining technique which produces red fluorescence when oxidized by superoxide and intercalates into DNA. At $72 \mathrm{~h}$ after the tMCAO, although limited fluorescent signal was detected in sham-operated rats, significantly higher fluorescence was found in the penumbral region of vehicle-treated ones (Figure $4 \mathrm{~A}, \mathrm{~B})$. Treatment with 8e markedly attenuated the production of superoxide $(20 \mathrm{mg} / \mathrm{kg}, p<0.01)$ as did AS252424 $(p<0.05)$.

We next determined the protein expression of NOX2 subunits which are regarded as the major source of superoxide in brain ischemia (Figure $4 \mathrm{C}-\mathrm{G}$ ). In this experiment, NOX2 was activated after $\mathrm{tMCAO}$, and the levels of its subunits were significantly increased ( $p<0.05$, respectively) except p22 ${ }^{\text {phox }} .8$ e did not affect the elevation of gp91 ${ }^{\text {phox }}$ although it effectively attenuated the expression of p47 phox and phosphorylation of p47phox at Ser328 (20 mg/ $\mathrm{kg}, p<0.05$, respectively). Meanwhile, AS252424 altered the levels of the $\mathrm{p}-\mathrm{p} 47^{\text {phox }}$ subunit with statistical significance $(p<0.05)$.

As mentioned above, abundant expression of NOX2 was found in microglia [16]. We further explored whether 8e could inhibit the activation of NOX2 in this cell type during tMCAO with double immunostaining of p47phox and Iba1 antibodies. Results in Figure $4 \mathrm{H}-\mathrm{J}$ showed that the Pearson's correlation coefficient of the vehicle-treated group was sharply raised at $72 \mathrm{~h}$ after tMCAO $(R r=0.512, p<0.001)$. Administration of $8 \mathbf{e}$ and AS252424 decreased the value of the Pearson's correlation coefficient (20 mg/ kg, $R r=0.360, p<0.05$; AS252424, $R r=0.323, p<0.01$ ). The ratios of $\mathrm{p} 47^{\mathrm{phox}} / \mathrm{Iba1}$ positive cells were profoundly reduced after $8 \mathbf{e}$ treatment at doses of $10 \mathrm{mg} / \mathrm{kg}$ and $20 \mathrm{mg} / \mathrm{kg}(p<0.05, p<0.001)$, while AS252424 had a similar effect $(p<0.01)$. These data indicated that 8 e prevents tMCAO-induced elevation of $\mathrm{p} 47^{\text {phox }}$ level in microglial cells. We therefore presumed that the effects of $8 \mathbf{e}$ on superoxide production may occur partly through inhibition of $\mathrm{p} 47^{\text {phox }}$ and p-p47phox in microglia after cerebral I/R in rats. Suppression of PI3K $\gamma$ by AS252424 could also decrease ROS generation and $\mathrm{p}^{4} 7^{\text {phox }}$ activation, indicating potential implication of $\mathrm{PI} 3 \mathrm{~K} \gamma$ signaling in the regulation of superoxide formation.

\subsection{8e Inhibited PI3K $\gamma$ Signaling in Microglia after Cerebral I/R in Rats}

Phosphorylation of AKT is a ubiquitous response to activation of Class I PI3K and has been suggested to trigger p47 ${ }^{\text {phox }}$-mediated ROS formation in leukocytes and endothelial cells [46]. We hypothesized that 8e may affect p47 phox through the PI3K $\gamma /$ AKT signaling pathway in activated microglial cells after stroke. According to our data, $\mathrm{PI} 3 \mathrm{~K} \gamma$ expression in the penumbral region is notably increased at $72 \mathrm{~h}$ following tMCAO, and this elevation was effectively eliminated by $8 \mathrm{e}$ $(10 \mathrm{mg} / \mathrm{kg}, p<0.05 ; 20 \mathrm{mg} / \mathrm{kg}, p<0.01)$. The protein level of $\mathrm{p}-\mathrm{AKT}$ was also reduced with the presence of $8 \mathbf{e}(20 \mathrm{mg} / \mathrm{kg}, p<0.05$; Figure $5 \mathrm{~A}-\mathrm{C})$. These results revealed that $8 \mathbf{e}$ could inhibit the $\mathrm{PI} 3 \mathrm{~K} \gamma / \mathrm{AKT}$ pathway in the context of stroke.

Considering the controversial location of $\mathrm{PI} 3 \mathrm{~K} \gamma$ in the CNS, we further assayed the cellular distribution of $\mathrm{PI} 3 \mathrm{~K} \gamma$ in the penumbral region of the ischemic brain with a double immunostaining technique (Figure 5D,E). PI3K $\gamma$ signals rose at $72 \mathrm{~h}$ after MCAO and were highly co-localized with Iba1 but not with NeuN, the marker for the soma of neurons. The Pearson's correlation coefficient of the vehicle-treated group in PI3K $\gamma / \mathrm{Iba} 1$ immunostaining exhibited a dramatic increase at $72 \mathrm{~h}$ after tMCAO $(R r=0.638, p<0.001)$, while this value in PI3K $\gamma / \mathrm{NeuN}$ immunostaining was barely changed $(R r=0.330, p>0.05)$, and those of the 8e-treated groups were reduced $(5 \mathrm{mg} / \mathrm{kg}, R r=0.398$, $p<0.01 ; 10 \mathrm{mg} / \mathrm{kg}, R r=0.395, p<0.01 ; 20 \mathrm{mg} / \mathrm{kg}, R r=0.251, p<0.001)$. The ratio of PI3K $\gamma / \mathrm{Iba} 1$ positive cells was remarkably reduced when given $20 \mathrm{mg} / \mathrm{kg}$ of $8 \mathbf{e}(p<0.001)$. Meanwhile, the ratios of PI3K $\gamma / \mathrm{NeuN}$-positive cells were not observably decreased in the presence of 8e. Our data showed that PI3K $\gamma$ was highly expressed in the microglia of the ischemic brain, and 8e could prevent cerebral $\mathrm{I} / \mathrm{R}$ injury via modulating the PI3K $\gamma / \mathrm{AKT}$ signaling pathway in microglia. 
A

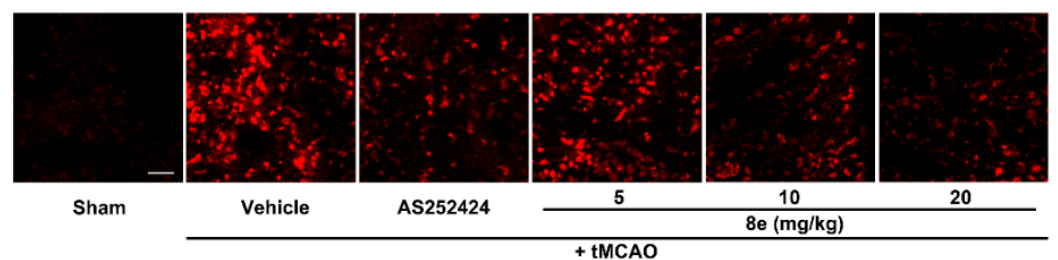

C

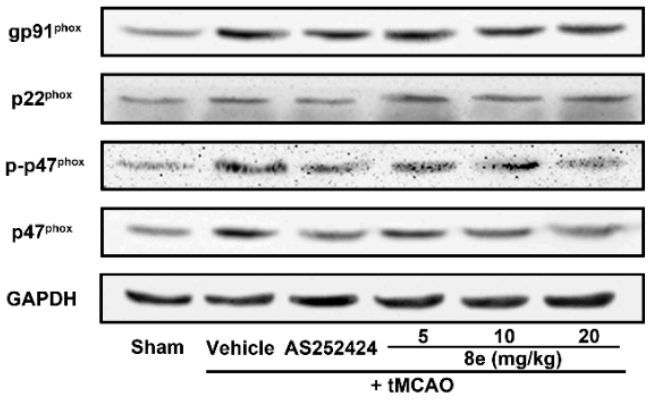

H
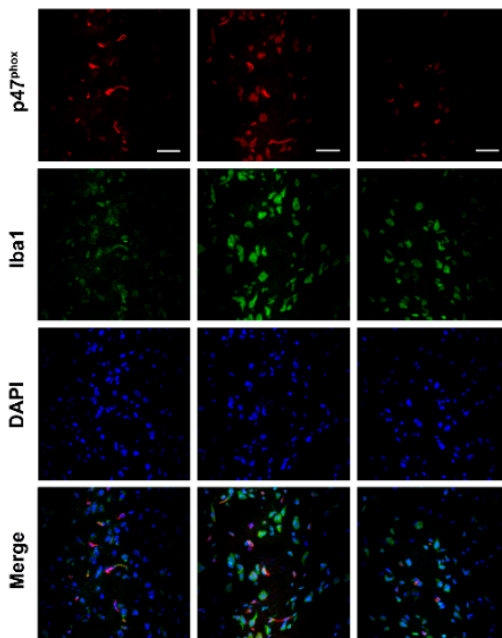

Sham

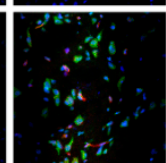

Vehicle
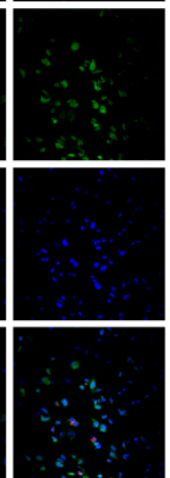

AS252424
D

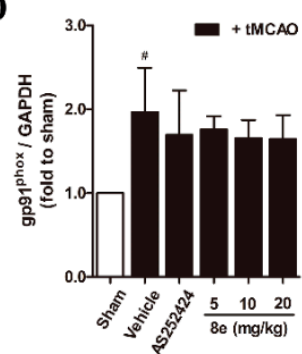

$F$

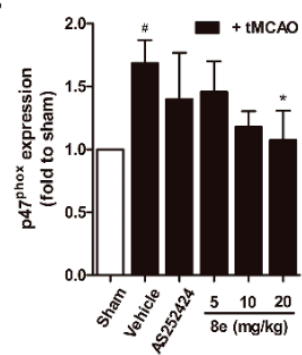

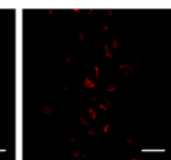
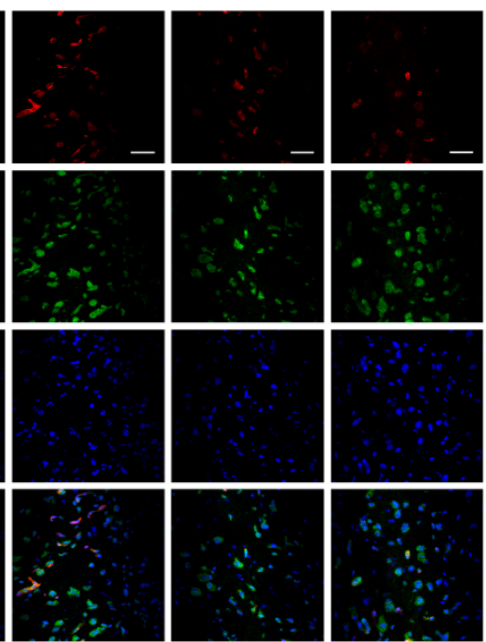

20
B

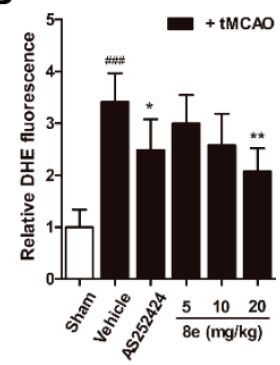

E

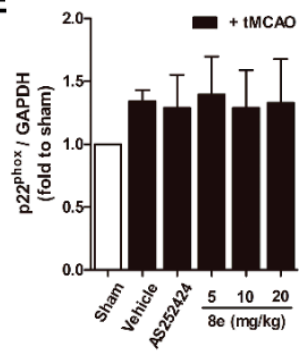

G

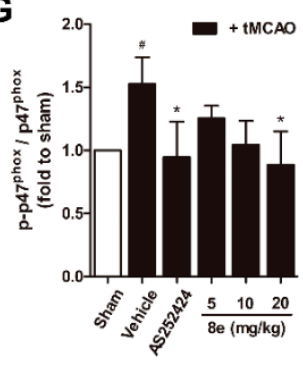

I

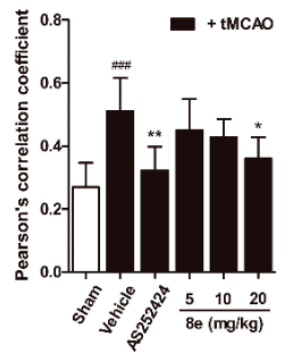

J

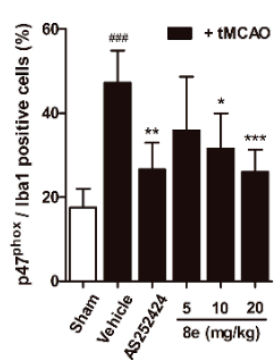

Figure 4. 8e attenuated superoxide production and the expression of $\mathrm{p} 47^{\mathrm{phox}}$ in microglia at $72 \mathrm{~h}$ after tMCAO in rats. (A) Representative images of DHE fluorescence in penumbral region. Scale bar $=50 \mu \mathrm{m}$; (B) semiquantitative analysis of superoxide production in DHE fluorescence; (C) representative bands of Western blot assay for gp91 phox, p22 $^{\text {phox }}$, p4 $7^{\text {phox }}$ and p-p47phox (Ser328) in penumbral region; (D-G) semiquantitative analysis of gp91 $1^{\text {phox }}, \mathrm{p} 22^{\text {phox }}, \mathrm{p} 47^{\text {phox }}$ and $\mathrm{p}-\mathrm{p} 47^{\text {phox }}$ protein levels; (H) representative confocal fluorescence images of penumbral region labeled with $\mathrm{p} 47^{\text {phox }}$ (red), Iba1 (green) antibodies and DAPI (blue). Scale bar $=50 \mu \mathrm{m}$; (I) Pearson's correlation coefficients between $\mathrm{p} 47^{\mathrm{phox}}$ (red) and Iba1 (green) fluorescence; (J) quantitative analysis of the percentage ratios of $\mathrm{p} 47^{\mathrm{phox}} / \mathrm{Iba} 1$ positive cells to Iba1 positive cells. Data are presented as mean $\pm \mathrm{SD}(n=3)$. ${ }^{\#} p<0.05$, \#\#\# $p<0.001$ vs. sham group. ${ }^{*} p<0.05,{ }^{* *} p<0.01,{ }^{* * *} p<0.001$ vs. tMCAO + vehicle group. 
A

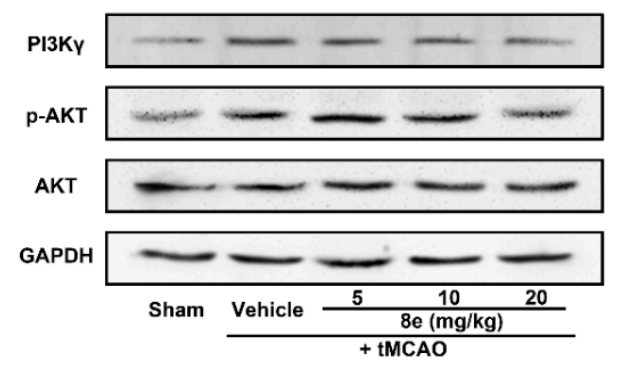

D

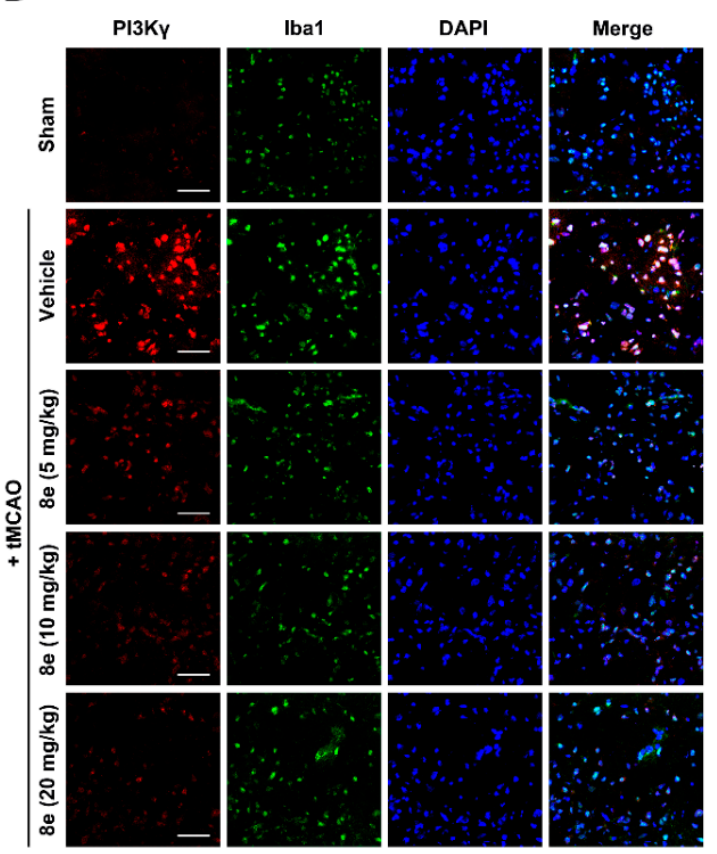

$\mathbf{F}$

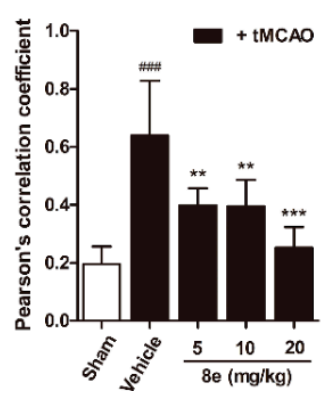

G

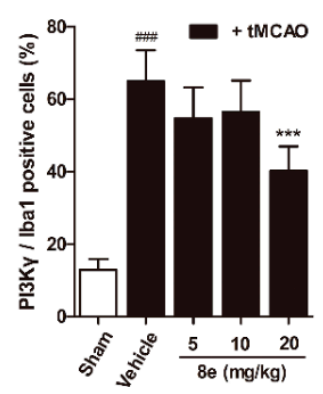

B

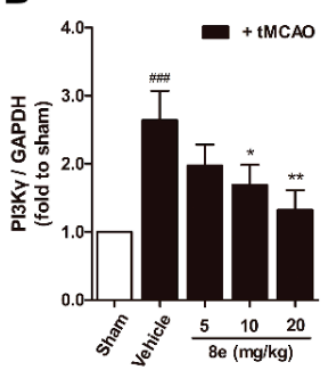

C

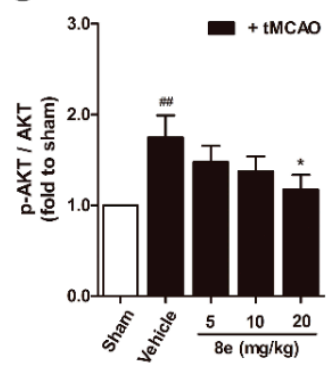

E

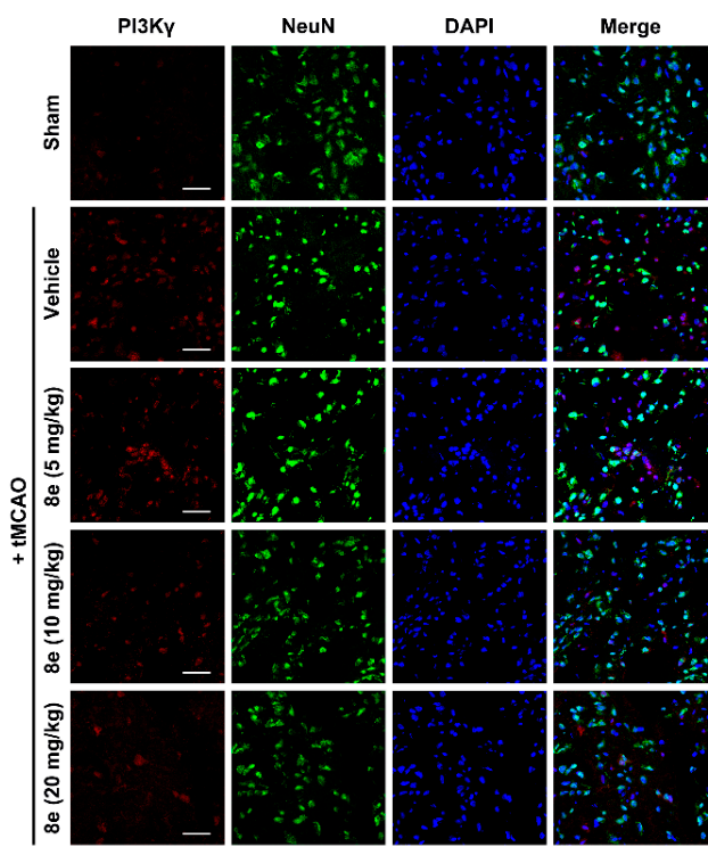

H

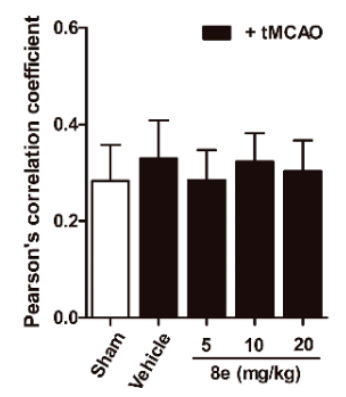

I

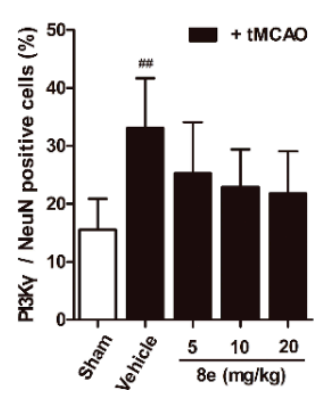

Figure 5. 8e inhibited phosphoinositide 3-kinase gamma (PI3K $\gamma$ ) signaling in microglia at $72 \mathrm{~h}$ after tMCAO in rats. (A) Representative bands of Western blot for PI3K $\gamma$, AKT and p-AKT in penumbral region; (B,C) semiquantitative analysis of PI3K $\gamma$ and p-AKT protein levels; (D) representative confocal fluorescence images of penumbral region labeled with PI3K $\gamma$ (red), Iba1 (green) antibodies and DAPI (blue). Scale bar $=50 \mu \mathrm{m}$; (E) representative confocal fluorescence images of penumbral region labeled with PI3K $\gamma$ (red), NeuN (green) antibodies and DAPI (blue). Scale bar $=50 \mu \mathrm{m} ;($ F) Pearson's correlation coefficients between PI3K $\gamma$ (red) and Iba1 (green) fluorescence; (G) quantitative analysis of the percentage ratios of PI3K $\gamma / \mathrm{Iba} 1$ positive cells to Iba1 positive cells; (H) Pearson's correlation coefficients between PI3K $\gamma$ (red) and NeuN (green) fluorescence; (I) quantitative analysis of the percentage ratios of PI3K $\gamma /$ NeuN positive cells to NeuN positive cells. Data are presented as mean $\pm \operatorname{SD}(n=3)$. ${ }^{\# \#} p<0.01$, \#\#\# $p<0.001$ vs. sham group. ${ }^{*} p<0.05,{ }^{* *} p<0.01,{ }^{* * *} p<0.001$ vs. tMCAO + vehicle group. 


\subsection{8e Down-Regulated PI3K $\gamma$ Signaling in OGD-Treated Primary Microglial Cells In Vitro}

We further conducted in vitro experiments to confirm whether 8e could affect the PI3K $\gamma /$ AKT signaling pathway in primary cultured microglial cells. As expected, PI3K $\gamma$ siRNA down-regulated the levels of PI3K $\gamma$ and p-AKT in microglia subjected to OGD ( $p<0.05$, respectively; Figure 6A-C). $10 \mu \mathrm{M} 8 \mathrm{e}$ significantly decreased the expression of PI3K $\gamma$ and $\mathrm{p}-\mathrm{AKT}(p<0.05$, respectively) and so did its combination with PI3K $\gamma$ siRNA (PI3K $\gamma, p<0.05$; $\mathrm{p}-\mathrm{AKT}, p<0.01$ ).

A

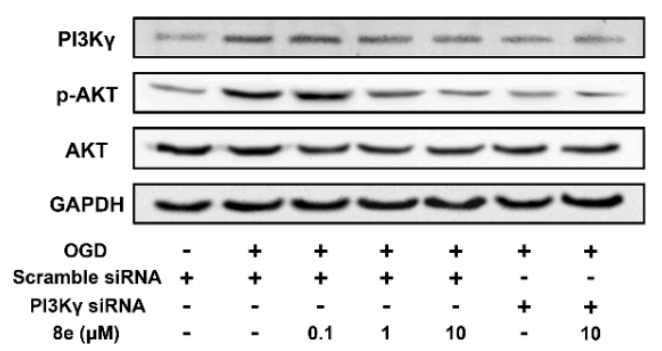

D

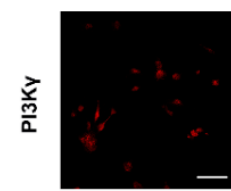

$\stackrel{\overline{5}}{\underline{5}}$

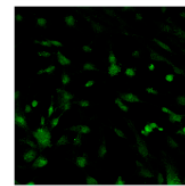

$\overline{\mathrm{a}}$

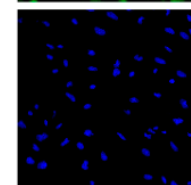

ฐুঁౖ

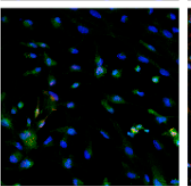

OGD

Scramble siRNA

PI3Ky siRNA

$8 \mathrm{e}(\mu \mathrm{M})$

\section{$+$}

10
B

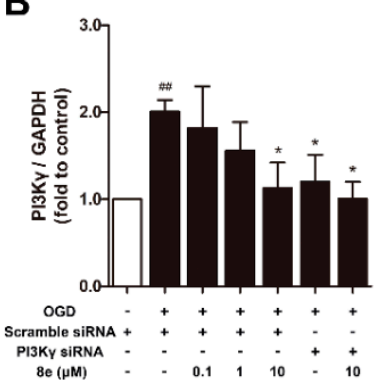

C
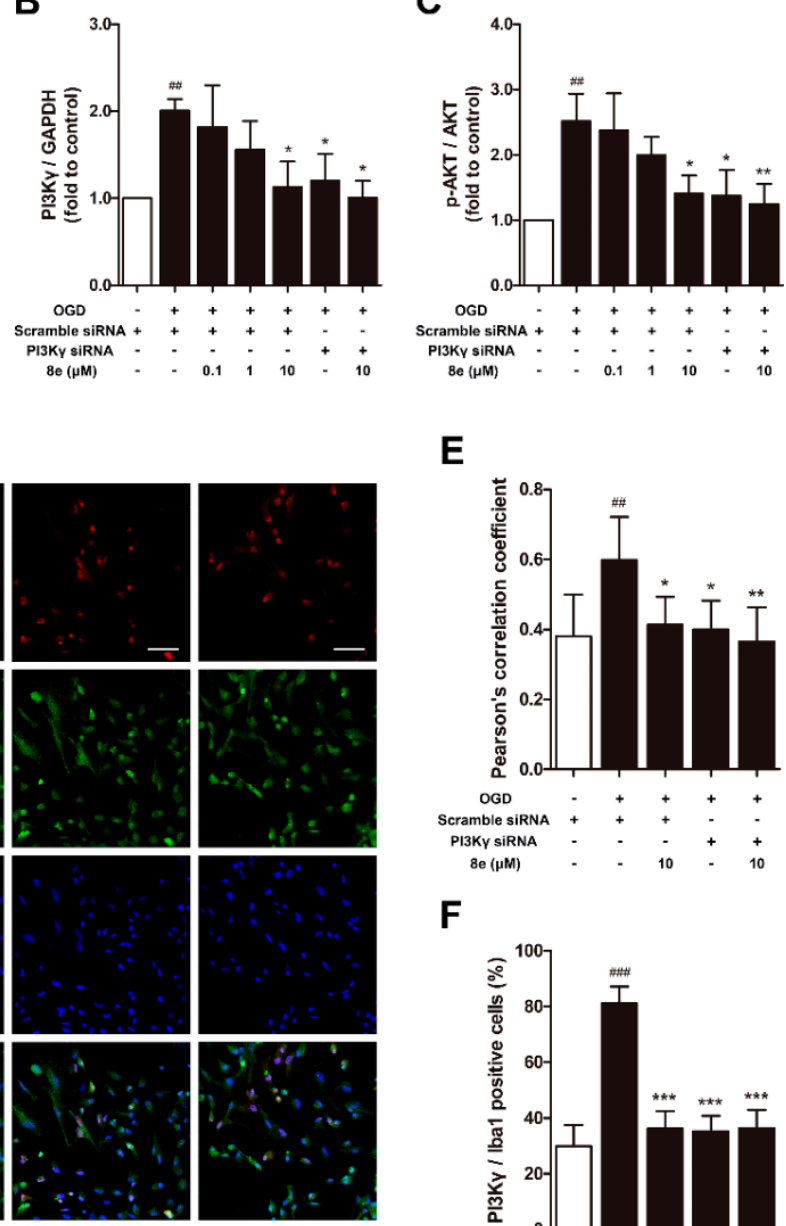

$+$
E

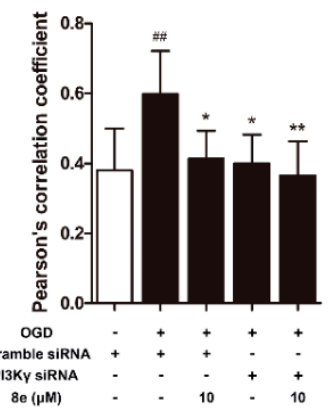

F

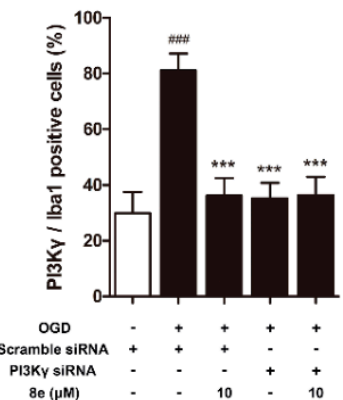

Figure 6. 8e downregulated PI3K $\gamma$ signaling in primary microglial cells at $24 \mathrm{~h}$ after oxygen-glucose deprivation (OGD). (A) Representative bands of Western blot for PI3K $\gamma$, AKT and p-AKT in primary microglia; (B,C) semiquantitative analysis of PI3K $\gamma$ and p-AKT protein levels; (D) representative confocal fluorescence images of primary microglia labeled with PI3K $\gamma$ (red), Iba1 (green) antibodies and DAPI (blue). Scale bar $=50 \mu \mathrm{m}$; (E) Pearson's correlation coefficients between PI3K $\gamma$ (red) and Iba1 (green) fluorescence; $(\mathbf{F})$ quantitative analysis of the percentage ratios of PI3K $\gamma / \mathrm{Iba} 1$ positive cells to Iba1 positive cells. Data are presented as mean $\pm \operatorname{SD}(n=3)$. ${ }^{\# \#} p<0.01,{ }^{\# \#} p<0.001$ vs. control group. ${ }^{*} p<0.05,{ }^{* *} p<0.01,{ }^{* * *} p<0.001$ vs. OGD group. 
In addition, for double immunostaining of PI3K $\gamma$ and Iba1 antibodies, the value of Pearson's correlation coefficient $(R r=0.400, p<0.05)$ and the ratio of PI3K $\gamma /$ Iba1 positive cells $(p<0.001)$ were much lessened in primary microglia by the blocking of PI3K $\gamma$ with siRNA (Figure 6D-F). $10 \mu \mathrm{M}$ 8e and its combination with $\mathrm{PI} 3 \mathrm{~K} \gamma$ siRNA exhibited similar inhibition on the fluorescent signal of PI3K $\gamma$ : Pearson's correlation coefficient $(8 \mathbf{e}, R r=0.413, p<0.05 ; 8 \mathbf{e}+\mathrm{PI} 3 \mathrm{~K} \gamma$ siRNA, $R r=0.365$, $p<0.01)$ and the ratios of PI3K $\gamma / \mathrm{Iba1}$ positive cells $(p<0.001$, respectively) were considerably reduced. However, no significant difference was found when comparing these two groups $(p>0.05$, respectively). These findings were consistent with our in vivo work showing that 8e could regulate PI3K $\gamma$ signaling in microglial cells.

\subsection{8e Modulated NOX2 through PI3K $\gamma / A K T$ Signaling in Microglia Subjected to OGD In Vitro}

As shown in Figure 7A-C, protein expressions of NOX2 subunits after OGD were monitored to confirm whether 8e regulates NOX2 through PI3K $\gamma$ signaling in primary microglia. Cells were treated with LY294002 and apocynin as PI3K/AKT and NOX2 inhibitors, respectively. The level of gp91 phox was affected by neither $10 \mu \mathrm{M}$ 8e nor its combination with PI3K $\gamma$ siRNA, LY294002, or even apocynin. These results indicated that $8 \mathbf{e}$ and apocynin do not modulate NOX2 via the gp91 ${ }^{\text {phox }}$ subunit. On the other hand, the elevation of p-p47phox caused by OGD was eliminated by $8 \mathbf{e}(p<0.01)$. Combinations of 8e with neither PI3K $\gamma$ siRNA, LY294002 nor apocynin further decrease the expression of p-p47phox when compared with $8 \mathbf{e}$ ( $p>0.05$, respectively). All these data demonstrated that 8e modulates the expression of $4^{4} 7^{\text {hox }}$ and its phosphorylation primarily through blocking of the PI3K $\gamma / \mathrm{AKT}$ pathway in OGD-treated microglia.

\subsection{8e Protected Neurons against Apoptosis by Down-Regulating Superoxide Production in OGD-Treated Primary Microglia In Vitro}

Activated microglia can induce and amplify cell damage to neighboring neurons by the excess production of cytotoxic factors such as superoxide, nitric oxide (NO) and tumor necrosis factor- $\alpha$ $(\mathrm{TNF} \alpha)$ [7]. In this part, we investigated whether 8e exerts neuroprotection through inhibition of superoxide formation in microglia subjected to OGD, with DHE staining. Administration of 8e profoundly ameliorated the production of DHE fluorescence $(p<0.05$, Figure 7D,E), while its combination with neither PI3K $\gamma$ siRNA nor apocynin further enhanced this effect in primary cultured microglia after OGD ( $p>0.05$, respectively).

Next, we found that neuronal apoptosis of TUNEL staining ascended sharply following co-culture of naïve neurons with OGD-treated microglia $(p<0.001$, Figure 7F,G). Single administration of $8 \mathbf{e}$ and PI3K $\gamma$ siRNA remarkably reduced the ratios of TUNEL positive cells $(p<0.01$, respectively), while its combination with neither PI3K $\gamma$ siRNA nor apocynin decreased the number further $(p>0.05$, respectively). We noticed that treatment with superoxide dismutase-1 (SOD) in culture media also attenuated neuronal apoptosis, but with less potency $(p<0.05)$. This finding partly confirmed that the superoxide generated in activated microglia enters extracellular space and spreads to nearby neurons [47]. Taken together, these results suggested that $8 \mathbf{e}$ could reduce the release of superoxide by microglia, and in turn protect neighboring neurons against apoptosis. 
A

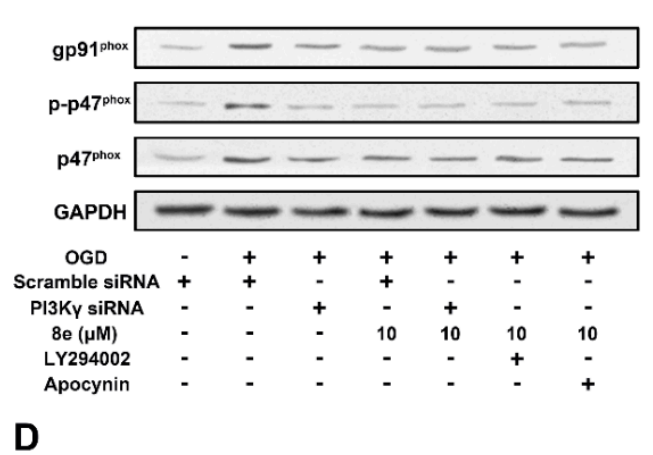

B

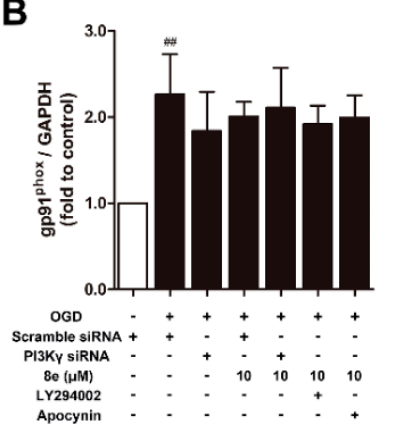

C

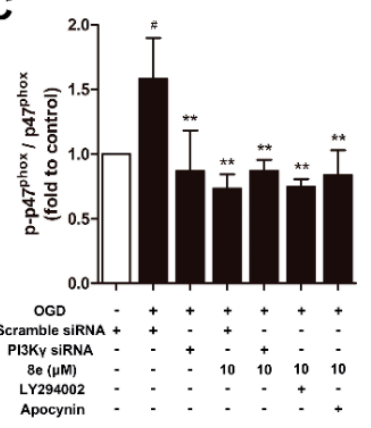

E

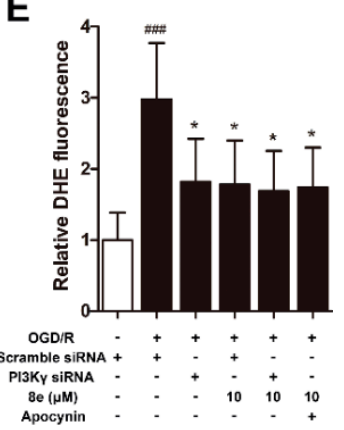

G

$\mathbf{F}$
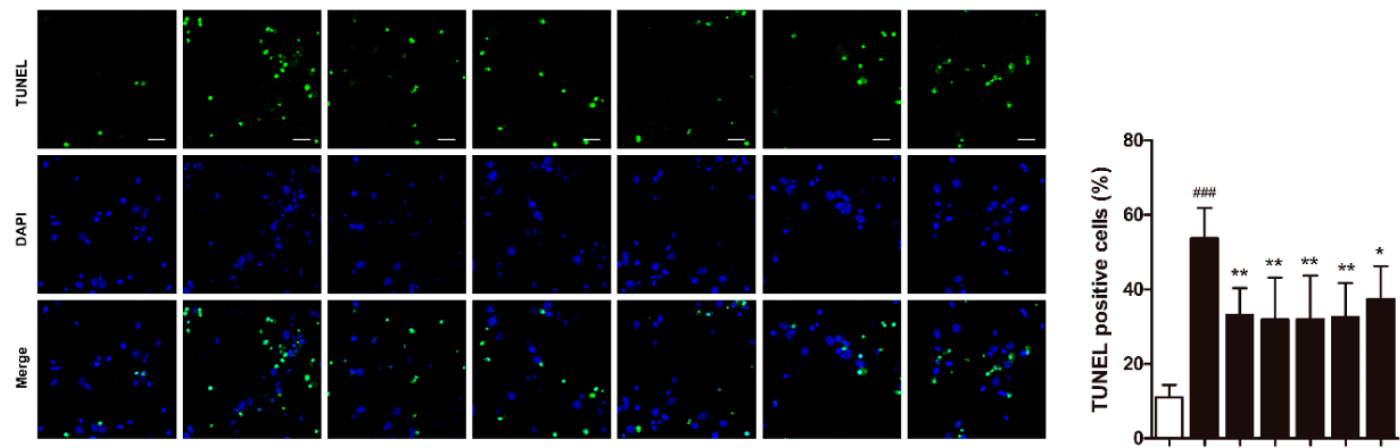

$\begin{array}{cc}\text { OGD/R } & - \\ \text { Scramble siRNA } & + \\ \text { PI3Ky siRNA } & - \\ \text { 8e }(\mu M) & - \\ \text { Apocynin } & - \\ \text { SOD } & -\end{array}$

$+$

+
-
+
-
-

+
-
+
10
-
-
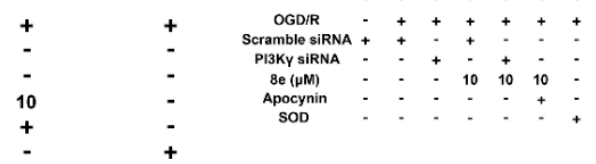

Figure 7. 8e modulated NOX2 through PI3K $\gamma /$ AKT signaling in primary microglial cells and protected neurons from apoptosis at $24 \mathrm{~h}$ after OGD. (A) Representative images of Western blot for gp91 ${ }^{\text {phox }}$, $\mathrm{p} 47^{\mathrm{phox}}$ and $\mathrm{p}-\mathrm{p} 47^{\mathrm{phox}}$ expressions in primary microglia; $(\mathrm{B}, \mathrm{C})$ semiquantitative analysis of gp91phox and $\mathrm{p}-\mathrm{p} 47^{\text {phox }}$ protein levels; (D) representative DHE fluorescence images of primary microglia at $24 \mathrm{~h}$ after OGD. Scale bar $=50 \mu \mathrm{m}$; (E) semiquantitative analysis of superoxide production in DHE fluorescence images; (F) representative TUNEL images of primary neurons counterstained with DAPI (blue). Scale bar $=20 \mu \mathrm{m} ;(\mathrm{G})$ quantitative analysis of the percentage ratios of TUNEL positive cells. Data are presented as mean $\pm \operatorname{SD}(n=3) .{ }^{\#} p<0.05,{ }^{\# \#} p<0.01,{ }^{\# \# \#} p<0.001$ vs. control group. ${ }^{*} p<0.05$, ** $p<0.01$, vs. OGD group.

\section{Discussion}

As a gasotransmitter, $\mathrm{H}_{2} \mathrm{~S}$ can rapidly travel across cell membranes without specific transporters, and hence has an impact on diverse physiological and pathological progresses [48]. A growing number of studies have shown that $\mathrm{H}_{2} \mathrm{~S}$ exerts cytoprotective activity primarily through anti-oxidative, anti-inflammatory, anti-apoptotic and pro-angiogenesis actions [37,49-51]. However, $\mathrm{H}_{2} \mathrm{~S}$ gas is not an ideal resource due to difficulties in concentration control and the risk of excessive toxicity [52]. Inorganic sulfide salts such as sodium sulfide $\left(\mathrm{Na}_{2} \mathrm{~S}\right)$ and sodium hydrogen sulfide $(\mathrm{NaHS})$ also release 
$\mathrm{H}_{2} \mathrm{~S}$ rapidly and spontaneously. Recently, a series of slow-releasing $\mathrm{H}_{2} \mathrm{~S}$ donors and hybrid drugs have been developed as new therapeutic approaches. They generate $\mathrm{H}_{2} \mathrm{~S}$ with lower levels of release rates and longer treatment intervals, in contrast to inorganic sulfide salts. A study by Whiteman et al. indicated that the effects of $\mathrm{H}_{2} \mathrm{~S}$ on inflammation depend not only on $\mathrm{H}_{2} \mathrm{~S}$ concentration but also on the rate of $\mathrm{H}_{2} \mathrm{~S}$ generation [53]. That may be one explanation for the seemingly controversial role of $\mathrm{H}_{2} \mathrm{~S}$ in inflammation-related diseases, such as stroke [38,54]. ADT and its main metabolite ADT-OH have been used extensively as a slow-releasing donor of $\mathrm{H}_{2} \mathrm{~S}$ [55]. Combinations of ADT-OH with L-DOPA and aspirin have shown protective properties in neurodegenerative processes [56,57].

3-n-butylphthalide (NBP) was approved by the China Food and Drug Administration (CFDA) in 2002 as a new drug for ischemic stroke treatment. Our group investigated a series of NBP derivatives combined with ADT-OH and reported that oral treatment with $\mathbf{8 e}$ provides superior antiplatelet and antithrombotic activities than NBP [36]. In this study, we verified the therapeutic effect of $8 \mathbf{e}$ in a rat model of transient focal cerebral ischemia. After a three-day intravenous treatment post tMCAO, 8e improved sensorimotor outcomes in three different behavioral assessments. The Longa test is one of the most frequently used neurological exams in rodent stroke studies. Although improvement trends were observed in all doses of 8e-treated groups, statistical significance was only found at $20 \mathrm{mg} / \mathrm{kg}$ following $48 \mathrm{~h}$ of reperfusion. This may be partly due to the fact that the Longa test focuses only on motor deficits. A recent study recommended the use of both Garcia and Longa tests to capture a broader range of neurological deficits [58]. The beam walking and prehensile traction tests are also widely applied in models of brain damage [59]. 8e markedly reduced the foot slip ratios and increased the length of time spent on the rope at $48 \mathrm{~h}$ and $72 \mathrm{~h}$ after tMCAO, indicating a protective capability of $8 \mathbf{e}$ in the sub-acute phase of ischemic stroke (Figure 2D-I). Meanwhile, we found that infarction volume and brain edema were notably decreased in the presence of $\mathbf{8 e}$, which provided solid evidence for its effectiveness. The results of histological examination and TUNEL staining in the penumbral region further confirmed these findings (Figure 3).

After stroke, inflammatory response is initiated in ischemic penumbra which is a metabolically active, but neurophysiologically silent, region surrounding the infarct core [60]. This response is characterized by rapid activation of microglia, production of proinflammatory mediators, and infiltration of various types of inflammatory cells including neutrophils, monocytes/macrophages, $\mathrm{T}$ cells and other cells [61]. Resident microglial cells are among the first cells to respond to brain injury. They are activated within minutes of ischemia onset and peak at 48-72 h [62]. Considering that activated microglia are morphologically and functionally indistinguishable from blood-derived monocytes/macrophages in the brain, Schilling et al. designed a series of experiments and confirmed that blood-derived macrophages are recruited at a later time and become abundant on days 3-7 [63-65]. Resident microglial activation precedes and predominates over blood-derived macrophage infiltration during the first three or four days of cerebral ischemia. Invasion of neutrophils occurs slightly later at $48 \mathrm{~h}$. However, the existence of neutrophils is largely masked after day three by the large-scale accumulation of activated microglia and macrophages in the penumbra region [66].

The experimental observations that PI $3 \mathrm{~K} \gamma$ is an important mediator in the signaling cascade of inflammatory response, have attracted worldwide attention to this kinase. But the role of PI3K $\gamma$ in the context of brain injury, has not been extensively studied. The level of PI3K $\gamma$ was significantly increased at one day and, up to seven days, after surgical brain injury in rats [26]. Similar up-regulation was found by Jin et al. in a mouse model of tMCAO within $24 \mathrm{~h}$ [27]. Here we reported for the first time that the protein expression of PI3K $\gamma$ is elevated in the penumbral region of rats at $72 \mathrm{~h}$ following cerebral ischemia (Figure $5 \mathrm{~A}, \mathrm{~B}$ ). We also detected the cellular location of PI3K $\gamma$ by a double immunostaining technique. PI3K $\gamma$ was colocalized with Iba1, a cell marker for microglia, while limited fluorescence signals of PI3K $\gamma$ were expressed in NeuN-positive neurons (Figure 5D-I). These data indicated that microglia may be the major cellular source of PI3K $\gamma$ in the penumbral region at day three after ischemic stroke. Our findings are consistent with the time course of inflammatory cell recruitment motioned above, suggesting PI3K $\gamma^{\prime}$ s involvement in microglial activation after tMCAO. Genetic 
ablation and pharmacological inhibition of PI3K $\gamma$ confer enhanced protection against Alzheimer's disease, surgical brain injury and cerebral ischemia $[25,26,28]$. On the other hand, the selective PI3K $\gamma$ inhibitor AS252424 at a dose of $10 \mathrm{mg} / \mathrm{kg}$ significantly attenuated surgical brain injury-induced brain edema and neurological deficits at 24 and $72 \mathrm{~h} \mathrm{[26].} \mathrm{In} \mathrm{our} \mathrm{research,} \mathrm{administration} \mathrm{of} \mathrm{AS252424,}$ a PI3K $\gamma$-selective inhibitor, attenuated sensorimotor deficits, infarction size and neural apoptosis following tMCAO (Figures 2 and 3), proving that inhibition of $\mathrm{PI} 3 \mathrm{~K} \gamma$ is a potential therapeutic strategy for neuroinflammation-mediated disorders. At the same time, $8 \mathbf{e}$ effectively down-regulated the level of PI3K $\gamma$ and improved I/R injury in vivo and in vitro (Figures 5 and 6). The combination of 8e with PI3K $\gamma$ siRNA did not further reduce the protein expression in primary cultured microglia, indicating that 8e exerts protective effect primarily through inhibition of $\mathrm{PI} 3 \mathrm{~K} \gamma$ signaling. Phosphatase and tensin homologue deleted on chromosome 10 (PTEN) negatively regulates the PI3K pathway and AKT activation. Recent reports showed that treatment with 25-100 $\mu \mathrm{M}$ NaHS reduced PTEN expression, whereas 800-1000 $\mu \mathrm{M}$ NaHS increased the level of PTEN protein in hepatocellular carcinoma cells [67]; however, the relative roles of $\mathrm{H}_{2} \mathrm{~S}$ donor in PTEN regulation in innate immune cells are still mostly unexplored.

Oxidative stress is implicated in acute brain injury and chronic neurodegenerative disorders [68]. Because of its high metabolic rate and relatively reduced capacity for cellular regeneration, the brain is extremely vulnerable to oxidative damage [69]. Unfortunately, therapies based on free radical scavenger or antioxidant principles have generally failed in clinical trials, despite the promising efficacy in preclinical studies. More and more researchers have shifted their focus onto ROS-generating pathways in various pathological situations. NADPH oxidases are considered the major source of ROS production, among which NOX2 is one of the most extensively studied isoforms during ischemic injury [70,71]. A strong increase of NOX2 was reported in resident microglial cells and recruited neutrophils after stroke onset [72]. A previous study has detected the robust production of superoxide at $4 \mathrm{~h}$ and its decrease within $24 \mathrm{~h}$ after reperfusion in WT mice, which were attributed to the enhanced neutrophil infiltration into the ischemic area [28]. They also found that the protein expression of NOX2 continuously increased until $72 \mathrm{~h}$ after tMCAO in WT mice. In the present study, elevation in the expression of NOX2 subunits and superoxide were observed at $72 \mathrm{~h}$ following cerebral ischemia in rats. This ROS generation and NOX2 activation at later time-points appears to be the consequence of microglial response to brain injury, as the infiltration of neutrophils has not reached its peak and their existence is masked in the sub-acute phase of stroke. Inhibition of PI3K $\gamma$ with AS252424 showed significant reductions in superoxide formation, the protein level of $\mathrm{p}-\mathrm{p} 47^{\mathrm{phox}}$ and the fluorescence signal of $\mathrm{p} 47^{\text {phox }}$ in microglia at $72 \mathrm{~h}$ after $\mathrm{tMCAO}$ (Figure 4). Similar results were found with the use of PI3K $\gamma$ siRNA in primary cultured microglia following OGD. 8e also exhibited equivalent effects on regulation of phosphorylated $\mathrm{p} 47^{\mathrm{phox}}$ and NOX2-derived superoxide in vivo and in vitro (Figure 7A-E). Furthermore, combination of 8e with neither PI3K $\gamma$ siRNA nor apocynin enhanced this effect in microglial cells. On the other hand, AKT is an established downstream of Class I PI3K, and it has been suggested that it is involved in the activation of $\mathrm{p} 47^{\text {phox }}$ in leukocytes and endothelial cells $[18,19]$. Our experimental data showed that, both 8e and blocking PI3K $\gamma$ eliminated the increase of p-AKT following I/R injury. The combination of $8 \mathbf{e}$ with LY294002, a PI3K/AKT inhibitor, did not further decrease the expression of $\mathrm{p}$-p4 $7^{\text {phox }}$ when compared with 8e. Taken together, these results demonstrate that $8 \mathbf{e}$ modulates $\mathrm{p} 47^{\mathrm{phox}}$ and its phosphorylation through PI3K $\gamma / \mathrm{AKT}$ signaling. With the use of a co-culture model, we also observed that superoxide generation from activated microglia enters extracellular space and spreads to nearby neurons. Administration of $\mathbf{8 e}$ and PI3K $\gamma$ siRNA to OGD-treated microglia markedly attenuated neuronal apoptosis in naïve neurons, suggesting that 8e protects neighboring neurons from apoptosis via control of superoxide generation in microglia (Figure 7F,G). 


\section{Materials and Methods}

\subsection{Chemicals}

8e (purity $>98 \%$ ) was synthesized by Jiangsu Key Laboratory of Drug Discovery for Metabolic Diseases, China Pharmaceutical University. PI3K $\gamma$-selective inhibitor AS252424, PI3K/AKT inhibitor LY294002, NOX2 inhibitor apocynin and superoxide dismutase-1 (SOD) were purchased from Aladdin Biotechnology, China. $0.9 \% \mathrm{NaCl}$ solution containing $5 \%$ ethanol and $5 \%$ polyethylene glycol $400 \mathrm{v} v / \mathrm{v}$, both from Sinopharm Chemical Reagent, Shanghai, China) was utilized as the vehicle.

\subsection{Animals}

All animal experimental protocols were approved by Ethics Committee of China Pharmaceutical University and performed in compliance with the Guideline on Administration of Laboratory Animals (China). Efforts were made to minimize the number of animals used and their suffering. Adult male Sprague-Dawley rats (250-280 g) were provided by the Comparative Medicine Centre of Yangzhou University (China) and housed under standard laboratory conditions of controlled temperature, humidity and a 12-hour light/dark cycle. The animals were allowed free access to food and water during one week of adaptation and fasted overnight before surgery.

\section{3. $t M C A O$ Surgery and Drug Treatment}

Transient middle cerebral artery occlusion was accomplished as previously described [73] to mimic human cerebral ischemia/reperfusion (I/R) injury. Briefly, after achieving general anesthesia by intraperitoneal injection of chloral hydrate $(300 \mathrm{mg} / \mathrm{kg}$, Sinopharm Chemical Reagent, Shanghai, China), the regional cerebral blood flow (rCBF) was monitored by Iaser Doppler flowmetry (LDF 100C, BIOPAC Systems, Goleta, California, USA). A 4-0 nylon monofilament suture with a rounded tip (Sunbio Biotechnology, Beijing, China) was inserted into the right internal carotid artery (ICA) through the external carotid artery (ECA) stump and gently advanced to block the origin of the middle cerebral artery (MCA). Restoration of MCA blood flow was accomplished by withdrawing the suture $60 \mathrm{~min}$ later. The sham-operated rats received the same surgery without suture insertion. Rats with unsuccessful occlusion (reduction of $\mathrm{rCBF}<75 \%$ ) and unsuccessful reperfusion (recovery of $\mathrm{rCBF}$ $<70 \%$ ) were excluded from the study [74]. The core body temperature was maintained at $37 \pm 0.5^{\circ} \mathrm{C}$ throughout the procedure.

Before surgery, rats were randomly divided into six groups, including sham, tMCAO + vehicle, $\mathrm{tMCAO}+10 \mathrm{mg} / \mathrm{kg}$ AS252424, $\mathrm{tMCAO}+5 \mathrm{mg} / \mathrm{kg} 8 \mathbf{e}, \mathrm{tMCAO}+10 \mathrm{mg} / \mathrm{kg} \mathbf{8 e}$, and $\mathrm{tMCAO}+20 \mathrm{mg} / \mathrm{kg}$ 8 groups. Among the 120 rats that underwent the tMCAO surgery, 4 rats were excluded for unsuccessful occlusion and 5 rats were excluded for unsuccessful reperfusion; 7 rats died during the surgery and 9 after the surgery. AS252424 and other drugs were administered intraperitoneally or intravenously at the beginning of reperfusion and repeated every $24 \mathrm{~h}$ for 3 days. The doses of $8 \mathbf{e}$ and AS252424 were calculated based on the clinical use of NBP and sodium chloride injection and previous report [26].

\subsection{Behavioral Assessment}

\subsubsection{Longa Test}

This neurological assessment is a 5 -point scale: 0 , no neurological deficit; 1 , failure to extend the left forepaw fully; 2 , circling to the left; 3 , falling to the left; and 4, no spontaneous walking and being depressed [75]. At $24 \mathrm{~h}, 48 \mathrm{~h}$ and $72 \mathrm{~h}$ after tMCAO, the performance of rats was evaluated by a blinded investigator.

\subsubsection{Beam Walking}

Fine motor coordination was assessed with the beam walking task. For 2 days before surgery, the rats were trained to traverse an elevated narrow beam $(2.5 \mathrm{~cm}$ in width, $1.2 \mathrm{~m}$ in length and $0.8 \mathrm{~m}$ in 
height) to enter a darkened goal box at the opposite end of beam. The test was conducted at $24 \mathrm{~h}, 48 \mathrm{~h}$ and $72 \mathrm{~h}$ after $\mathrm{tMCAO}$ and the performance of the rats was videotaped and analyzed by calculating the foot slip ratios of the impaired limbs (number of foot faults/number of total steps) by a blinded investigator. A fault was defined as any foot slip off the top surface of the beam or any limb use on the side of the beam [76].

\subsubsection{Prehensile Traction}

A $0.6 \mathrm{~m}$ long and $4 \mathrm{~mm}$ diameter wire was placed horizontally $0.4 \mathrm{~m}$ above a foam pad [59]. At $24 \mathrm{~h}, 48 \mathrm{~h}$ and $72 \mathrm{~h}$ after $\mathrm{tMCAO}$, the animals were released with their forepaws placed onto the rope to evaluate muscle strength and equilibrium. The time to falling (maximum $60 \mathrm{~s}$ ) was noted.

\subsection{Infarct Volume and Brain Edema Measurement}

At $72 \mathrm{~h}$ after $\mathrm{tMCAO}$, rats were deeply anesthetized with a lethal dose of chloral hydrate $\left(350 \mathrm{mg} / \mathrm{kg}\right.$ ) and the brains were frozen at $-20{ }^{\circ} \mathrm{C}$ for $20 \mathrm{~min}$. The frozen brains were cut into 2-mm-thick coronal sections and stained with $2 \%$ of 2,3,5-Triphenyltetrazolium chloride (TTC, Sigma-Aldrich, St. Louis, MO, USA) for $20 \mathrm{~min}$ at $37^{\circ} \mathrm{C}$. The brain slices were then fixed in $4 \%$ formaldehyde overnight at room temperature and photographed with a digital camera. The area of infarction in each slice was measured using Image J (NIH, Bethesda, MD, USA), and infarct volume was obtained from the product of average thickness $(2 \mathrm{~mm})$ and the sum of infarction areas in all slices examined. Infarct volume $(\%)=$ total infarct volume/total brain volume $\times 100 \%$.

Brain edema was evaluated by measuring the brain water content as previously described [77]. Brains were rapidly removed at $72 \mathrm{~h}$ post reperfusion and both hemispheres were weighed before and after drying at $100{ }^{\circ} \mathrm{C}$ for $24 \mathrm{~h}$. The brain water content $(\%)=(1-$ dry weight $/$ wet weight $) \times 100 \%$.

\subsection{Primary Microglia Culture}

Microglial culture was prepared as previously described with modification [74]. The brain of postnatal (P0-2) Sprague-Dawley (SD) rats was separated and the meninges were carefully removed. The cerebral cortex was cut into small fragments and digested with trypsin $(0.25 \%$, Sigma-Aldrich, St. Louis, MO, USA) for $10 \mathrm{~min}$ at room temperature. The cell suspension was filtered through $100-\mu \mathrm{m}$ and 40- $\mu \mathrm{m}$ cell strainers (BD Falcon, Bedford, MA, USA). After centrifugation for 5 min at $100 \mathrm{~g}$, the pallet was resuspended in Dulbecco's modified Eagle's medium/Ham's nutrient mixture F-12 (DMEM/F12) containing 10\% fetal bovine serum (FBS) and seeded into poly-lysine $(0.1 \mathrm{mg} / \mathrm{mL}$, Sigma-Aldrich, St. Louis, MO, USA) pre-coated $75-\mathrm{cm}^{2}$ flasks in a humidified incubator $\left(95 \% \mathrm{O}_{2}\right.$, $5 \% \mathrm{CO}_{2}, 37^{\circ} \mathrm{C}$ ). Culture media were changed every 2 days. Two weeks later, the isolation of microglia was accomplished by gentle shaking of the culture flask. The collected cells were seeded into 24-well plates with coverslips, or the upper inserts of Transwell chambers $(0.4 \mu \mathrm{m}$ diameter pores, Corning, NY, USA).

\section{7. siRNA Transfection and OGD Treatment}

PI3K $\gamma$ siRNA and negative control (40 nM, all from GenePharma, Shanghai, China) were transfected into primary cultured microglia using Lipofectamine 2000 (Thermo Fisher Scientific, San Jose, CA, USA) $24 \mathrm{~h}$ post cell seeding. PI3K $\gamma$ siRNA consisted of an RNA duplex containing a sense strand 5'-GCA UUG AUA UCC CUG UCU UTT-3' and an antisense strand 5'-AAG ACA GGG AUA UCA AUG CTT-3'.

$48 \mathrm{~h}$ after transfection, microglia were subjected to OGD by replacing the culture media with glucose free DMEM containing 2\% FBS and transferring to an OGD incubator chamber $\left(95 \% \mathrm{~N}_{2}\right.$, $\left.5 \% \mathrm{CO}_{2}, 37^{\circ} \mathrm{C}\right)$. After $1 \mathrm{~h}$ of OGD, the plates were removed from the chamber and the culture media were replaced with DMEM/F12 and 2\% FBS to achieve reoxygenation. Microglial cells were harvested for further experimentation $24 \mathrm{~h}$ post reoxygenation. Drug treatments including LY294002 
$(10 \mu \mathrm{M})$, apocynin $(1 \mathrm{mM})$ and SOD $(200 \mathrm{U} / \mathrm{mL})$ were applied to the cell culture $2 \mathrm{~h}$ before and during OGD/reoxygenation.

\subsection{Primary Neuron Culture and Neuron-Microglia Co-Culture}

Primary neuron cultures were prepared using embryos (E16-18) of SD rats. The cortex of the brainwas dissected and digested with $800 \mathrm{U}$ DNase I and $2 \mathrm{mg} / \mathrm{mL}$ papain (both from Biosharp, Hefei, Anhui, China) at $37^{\circ} \mathrm{C}$ for $30 \mathrm{~min}$ [78]. The cell suspension was filtered through $40-\mu \mathrm{m}$ cell strainers (BD Falcon, Bedford, MA, USA). After centrifugation for $5 \mathrm{~min}$ at $100 \mathrm{~g}$, the cells were resuspended in DMEM/F12 containing 10\% FBS and seeded into poly-l-lysine pre-coated lower wells of Transwell chambers with coverslips. The culture media were replaced by Neurobasal medium supplemented with 2\% B27 (both from Gibco, Carlsbad, CA, USA) after $4 \mathrm{~h}$ of incubation. Half of the media were replaced with fresh Neurobasal/B27 every 4 days.

After 7-10 days of incubation, the lower wells containing naïve neurons were allowed to communicate with microglia subjected to $1 \mathrm{~h}$ of OGD in the upper inserts of the Transwell chambers for $24 \mathrm{~h}\left(95 \% \mathrm{~N}_{2}, 5 \% \mathrm{CO}_{2}, 37^{\circ} \mathrm{C}\right)$. The culture media were all replaced with Neurobasal/B27.

\subsection{Histological Observation and Apoptosis Analysis}

Rats were anesthetized with $350 \mathrm{mg} / \mathrm{kg}$ of chloral hydrate and intracardially perfused with iced normal saline followed by $4 \%$ paraformaldehyde (PFA, Sinopharm Chemical Reagent, Shanghai, China) at $72 \mathrm{~h}$ after tMCAO. The brains were post-fixed in PFA overnight and embedded in paraffin. Microglia-bearing coverslips were removed from the 24-well plates $24 \mathrm{~h}$ after OGD, then fixed with 4\% PFA for $30 \mathrm{~min}$ and permeabilized with $0.1 \%$ Triton X-100 (Sigma-Aldrich, St. Louis, $\mathrm{MO}, \mathrm{USA}$ ). For histological observation, $5-\mu \mathrm{m}$ brain slices at the level of bregma +0.7 to $-4.3 \mathrm{~mm}$ were counterstained with hematoxylin and eosin. Terminal deoxynucleotidyl transferase dUTP nick end labeling (TUNEL) staining were conducted on both brain slices and coverslips according to manufacturer's instructions (KeyGEN Biotech, Nanjing, China). Tissue sections of the penumbral regions were observed under a microscope with 200× magnification (CKX41, Olympus, Tokyo, Japan). Cell TUNEL staining was captured with a confocal microscope (LSM700, Zeiss, Oberkochen, Germany). The numbers of TUNEL-positive cells were analyzed by a blinded investigator with Image J.

\subsection{Oxidative Stress Evaluation}

$72 \mathrm{~h}$ after $\mathrm{tMCAO}$, the animals were anesthetized with $350 \mathrm{mg} / \mathrm{kg}$ of chloral hydrate and perfused with iced normal saline through the heart. $5-\mu \mathrm{m}$ frozen brain slices at the level of bregma +0.7 to -4.3 $\mathrm{mm}$ were cut on a CM1950 cryostat (Leica, Wetzlar, Germany) and further fixed in acetone for $10 \mathrm{~min}$ at $4{ }^{\circ} \mathrm{C}$. Microglia-bearing coverslips were prepared as mentioned above. The slides and coverslips were incubated with $2.5 \mu \mathrm{M}$ dihydroethidium (DHE, Beyotime Biotechnology, Shanghai, China) at $37^{\circ} \mathrm{C}$ for $30 \mathrm{~min}$ in a humidified chamber which was shielded from light [79]. DHE produces red fluorescence when oxidized to ethidium by superoxide anion and intercalates into DNA. Fluorescent images were acquired using a confocal microscope. The mean fluorescence intensity for each region (integrated density/area) of the penumbral regions was blind-analyzed by Image J and normalized to the level of the sham or control group.

\subsection{Immunofluorescent Staining}

Frozen brain slices and microglia-bearing coverslips mentioned above were immunostained as previously described [80]. Briefly, after incubation with primary antibodies of p47phox (1:200, Sigma-Aldrich, St. Louis, MO, USA), PI3K $\gamma$ (1:500, Novus, Littleton, CO, USA), Iba1 (1:500, Millipore, Billerica, MA, USA) and NeuN (1:500, Millipore, Billerica, MA, USA), antibody binding was visualized with Alexa Fluor 488-labeled goat anti-mouse IgG and Cy3-labeled goat anti-rabbit $\operatorname{IgG}(1: 200$, both from Beyotime Biotechnology, Shanghai, China). Cell nuclei were counterstained with 4',6-diamidino-2-phenylindole (DAPI). Images of the penumbral regions were obtained using a 
confocal microscope. The Pearson's correlation coefficient and the numbers of antibody-positive cells were analyzed by a blinded investigator using Image J.

\subsection{Western Blotting}

Total protein was prepared from the penumbral regions at the level of bregma +0.7 to $-4.3 \mathrm{~mm} 72 \mathrm{~h}$ after tMCAO, and primary cultured cells $24 \mathrm{~h}$ after OGD as reported previously [81]. Samples were homogenized in iced radio immunoprecipitation assay (RIPA) buffer supplemented with protease and phosphatase inhibitor cocktail (all from Beyotime Biotechnology, Shanghai, China). Following centrifugation at $13,000 \mathrm{~g}$ for $20 \mathrm{~min}$ at $4{ }^{\circ} \mathrm{C}$, the supernatant was collected. Equal amounts of protein $(20 \mu \mathrm{g})$ were loaded onto $8-10 \%$ sodium dodecyl sulfate polyacrylamide gel electrophoresis (SDS-PAGE) gels and transferred to polyvinylidene fluoride (PVDF) membranes (Millipore, Billerica, MA, USA). Membranes were blocked with 5\% non-fat milk in Tris-Buffered Saline with Tween 20 $(0.1 \%, v / v, \mathrm{TBST})$ for $1 \mathrm{~h}$ at room temperature, and incubated overnight at $4{ }^{\circ} \mathrm{C}$ with primary antibodies against PI3K $\gamma$, gp91 ${ }^{\text {phox }}$, p22 ${ }^{\text {phox }}$, p47 $^{\text {phox }}$ (all from Santa Cruz Biotechnology, Dallas, TX, USA), phosphorylation-p47 ${ }^{\text {phox }}$ at Ser328 (Abcam, Cambridge, MA, USA), AKT, phosphorylation-AKT at Ser473 and GAPDH (all from Cell Signaling Technology, Danvers, MA, USA). Then the membranes were hybridized with the appropriate horseradish peroxidase (HRP) conjugated secondary antibodies (1:5000, Cell Signaling Technology, Danvers, MA, USA) for $1 \mathrm{~h}$ at room temperature. Protein expression was detected by the enhanced chemiluminescence (ECL) method on an imaging system (ChmiScope 2850; Clinx Science Instruments, Shanghai, China) and normalized to internal reference.

\subsection{Statistical Analysis}

Data are presented as the mean $\pm \mathrm{SD}$. All statistical analyses were performed using GraphPad Prism 5.0 (GraphPad Software, San Diego, CA, USA). All behavioral data were analyzed using repeated measures ANOVA. Group differences were ascertained using Dunn or Tukey post hoc comparisons where appropriate. As the normality test with the Kolmogorov-Smirnov test was passed, the rest of the data were analyzed by one-way ANOVA with Tukey's post hoc test. $p<0.05$ was considered statistically significant.

\section{Conclusions}

Our study demonstrated that $\mathbf{8 e}$ attenuates sensorimotor deficits, focal infarction and neural apoptosis in cerebral ischemia. 8e may exert protective effects partly thorough regulation of superoxide production in activated microglia via the PI $3 \mathrm{~K} \gamma / \mathrm{AKT} / \mathrm{NOX} 2$ signaling pathway. These findings about 8e widen our knowledge of $\mathrm{H}_{2} \mathrm{~S}$-releasing compounds and provide a novel direction for stroke research.

Author Contributions: L.W., Y.Z. and H.J. conceived and designed the experiments; X.W. synthesized the compound 8e; L.W., X.W. and T.L. performed the experiments; T.L. analyzed the data; L.W. and H.J. wrote the paper.

Funding: This work was supported by the National Natural Science Foundation of China (No. 81872867, No. 81503150, No. 21502071), the Priority Academic Program Development of Jiangsu Higher Education Institutions and the Policy Directive Program of Jiangsu Province (BY2015072-03).

Acknowledgments: The authors would like to express their gratitude to the core facility of State Key Laboratory of Natural Medicines, China Pharmaceutical University.

Conflicts of Interest: The authors declare no conflicts of interest.

\section{References}

1. Benjamin, E.J.; Blaha, M.J.; Chiuve, S.E.; Cushman, M.; Das, S.R.; Deo, R.; de Ferranti, S.D.; Floyd, J.; Fornage, M.; Gillespie, C.; et al. Heart Disease and Stroke Statistics-2017 Update A Report from the American Heart Association. Circulation 2017, 135, E146-E603. [CrossRef] [PubMed] 
2. Hacke, W.; Kaste, M.; Bluhmki, E.; Brozman, M.; Davalos, A.; Guidetti, D.; Larrue, V.; Lees, K.R.; Medeghri, Z.; Machnig, T.; et al. Thrombolysis with alteplase 3 to 4.5 hours after acute ischemic stroke. N. Engl. J. Med. 2008, 359, 1317-1329. [CrossRef] [PubMed]

3. Molina, C.A. Reperfusion Therapies for Acute Ischemic Stroke Current Pharmacological and Mechanical Approaches. Stroke 2011, 42, S16-S19. [CrossRef] [PubMed]

4. Lo, E.H. Experimental models, neurovascular mechanisms and translational issues in stroke research. Br. J. Pharmacol. 2008, 153, S396-S405. [CrossRef] [PubMed]

5. Moskowitz, M.A.; Lo, E.H.; Iadecola, C. The Science of Stroke: Mechanisms in Search of Treatments. Neuron 2010, 67, 181-198. [CrossRef] [PubMed]

6. Lo, E.H. A new penumbra: Transitioning from injury into repair after stroke. Nat. Med. 2008, 14, 497-500. [CrossRef] [PubMed]

7. Block, M.L.; Zecca, L.; Hong, J.S. Microglia-mediated neurotoxicity: Uncovering the molecular mechanisms. Nat. Rev. Neurosci. 2007, 8, 57-69. [CrossRef] [PubMed]

8. Patel, A.R.; Ritzel, R.; McCullough, L.D.; Liu, F. Microglia and ischemic stroke: A double-edged sword. Int. JPPP 2013, 5, 73-90.

9. Nimmerjahn, A.; Kirchhoff, F.; Helmchen, F. Resting microglial cells are highly dynamic surveillants of brain parenchyma in vivo. Science 2005, 308, 1314-1318. [CrossRef] [PubMed]

10. Iadecola, C.; Anrather, J. The immunology of stroke: From mechanisms to translation. Nat. Med. 2011, 17, 796-808. [CrossRef] [PubMed]

11. Schwartz, M.; Butovsky, O.; Bruck, W.; Hanisch, U.K. Microglial phenotype: Is the commitment reversible? Trends Neurosci. 2006, 29, 68-74. [CrossRef] [PubMed]

12. Biber, K.; Owens, T.; Boddeke, E. What is microglia neurotoxicity (Not)? Glia 2014, 62, 841-854. [CrossRef] [PubMed]

13. Mander, P.K.; Jekabsone, A.; Brown, G.C. Microglia proliferation is regulated by hydrogen peroxide from NADPH oxidase. J. Immunol. 2006, 176, 1046-1052. [CrossRef] [PubMed]

14. Kauppinen, T.M.; Higashi, Y.; Suh, S.W.; Escartin, C.; Nagasawa, K.; Swanson, R.A. Zinc triggers microglial activation. J. Neurosci. 2008, 28, 5827-5835. [CrossRef] [PubMed]

15. Konior, A.; Schramm, A.; Czesnikiewicz-Guzik, M.; Guzik, T.J. NADPH Oxidases in Vascular Pathology. Antioxid. Redox Signal. 2014, 20, 2794-2814. [CrossRef] [PubMed]

16. Zhang, Y.; Chen, K.; Sloan, S.A.; Bennett, M.L.; Scholze, A.R.; O'Keeffe, S.; Phatnani, H.P.; Guarnieri, P.; Caneda, C.; Ruderisch, N.; et al. An RNA-sequencing transcriptome and splicing database of glia, neurons, and vascular cells of the cerebral cortex. J. Neurosci. 2014, 34, 11929-11947. [CrossRef] [PubMed]

17. Brandes, R.P.; Weissmann, N.; Schröder, K. Nox family NADPH oxidases: Molecular mechanisms of activation. Free Radic. Biol. Med. 2014, 76, 208-226. [CrossRef] [PubMed]

18. Hoyal, C.R.; Gutierrez, A.; Young, B.M.; Catz, S.D.; Lin, J.H.; Tsichlis, P.N.; Babior, B.M. Modulation of p47PHOX activity by site-specific phosphorylation: Akt-dependent activation of the NADPH oxidase. Proc. Natl. Acad. Sci. USA 2003, 100, 5130-5135. [CrossRef] [PubMed]

19. Chatterjee, S.; Browning, E.A.; Hong, N.K.; DeBolt, K.; Sorokina, E.M.; Liu, W.D.; Birnbaum, M.J.; Fisher, A.B. Membrane depolarization is the trigger for PI3K/Akt activation and leads to the generation of ROS. Am. J. Physiol. Heart C 2012, 302, H105-H114. [CrossRef] [PubMed]

20. Okkenhaug, K. Signaling by the Phosphoinositide 3-Kinase Family in Immune Cells. Annu. Rev. Immunol. 2013, 31, 675-704. [CrossRef] [PubMed]

21. Camps, M.; Ruckle, T.; Ji, H.; Ardissone, V.; Rintelen, F.; Shaw, J.; Ferrandi, C.; Chabert, C.; Gillieron, C.; Francon, B.; et al. Blockade of PI3Kgamma suppresses joint inflammation and damage in mouse models of rheumatoid arthritis. Nat. Med. 2005, 11, 936-943. [CrossRef] [PubMed]

22. Barber, D.F.; Bartolome, A.; Hernandez, C.; Flores, J.M.; Redondo, C.; Fernandez-Arias, C.; Camps, M.; Ruckle, T.; Schwarz, M.K.; Rodriguez, S.; et al. PI3Kgamma inhibition blocks glomerulonephritis and extends lifespan in a mouse model of systemic lupus. Nat. Med. 2005, 11, 933-935. [CrossRef] [PubMed]

23. Siragusa, M.; Katare, R.; Meloni, M.; Damilano, F.; Hirsch, E.; Emanueli, C.; Madeddu, P. Involvement of Phosphoinositide 3-Kinase gamma in Angiogenesis and Healing of Experimental Myocardial Infarction in Mice. Circ. Res. 2010, 106, 757-768. [CrossRef] [PubMed] 
24. Ruckle, T.; Schwarz, M.K.; Rommel, C. PI3K gamma inhibition: Towards an 'aspirin of the 21st century'? Nat. Rev. Drug Discov. 2006, 5, 903-918. [CrossRef] [PubMed]

25. Passos, G.F.; Figueiredo, C.P.; Prediger, R.D.S.; Silva, K.A.B.S.; Siqueira, J.M.; Duarte, F.S.; Leal, P.C.; Medeiros, R.; Calixto, J.B. Involvement of phosphoinositide 3-kinase gamma in the neuro-inflammatory response and cognitive impairments induced by beta-amyloid 1-40 peptide in mice. Brain Behav. Immun. 2010, 24, 493-501. [CrossRef] [PubMed]

26. Huang, L.; Sherchan, P.; Wang, Y.; Reis, C.; Applegate, R.L., 2nd; Tang, J.; Zhang, J.H. Phosphoinositide 3-Kinase Gamma Contributes to Neuroinflammation in a Rat Model of Surgical Brain Injury. J. Neurosci. 2015, 35, 10390-10401. [CrossRef] [PubMed]

27. Jin, R.; Yu, S.; Song, Z.; Quillin, J.W.; Deasis, D.P.; Penninger, J.M.; Nanda, A.; Granger, D.N.; Li, G. Phosphoinositide 3-kinase-gamma expression is upregulated in brain microglia and contributes to ischemia-induced microglial activation in acute experimental stroke. Biochem. Biophys. Res. Commun. 2010, 399, 458-464. [CrossRef] [PubMed]

28. Jin, R.; Song, Z.F.; Yu, S.Y.; Piazza, A.; Nanda, A.; Penninger, J.M.; Granger, D.N.; Li, G.H. Phosphatidylinositol3-Kinase Gamma Plays a Central Role in Blood-Brain Barrier Dysfunction in Acute Experimental Stroke. Stroke 2011, 42, 2033-2044. [CrossRef] [PubMed]

29. Schmidt, C.; Frahm, C.; Schneble, N.; Muller, J.P.; Brodhun, M.; Franco, I.; Witte, O.W.; Hirsch, E.; Wetzker, R.; Bauer, R. Phosphoinositide 3-Kinase gamma Restrains Neurotoxic Effects of Microglia After Focal Brain Ischemia. Mol. Neurobiol. 2016, 53, 5468-5479. [CrossRef] [PubMed]

30. Kim, J.I.; Lee, H.R.; Sim, S.E.; Baek, J.; Yu, N.K.; Choi, J.H.; Ko, H.G.; Lee, Y.S.; Park, S.W.; Kwak, C.; et al. PI3K gamma is required for NMDA receptor-dependent long-term depression and behavioral flexibility. Nat. Neurosci. 2011, 14, 1447-1454. [CrossRef] [PubMed]

31. Li, L.; Rose, P.; Moore, P.K. Hydrogen Sulfide and Cell Signaling. Annu. Rev. Pharmacol. 2011, 51, $169-187$. [CrossRef] [PubMed]

32. Gao, Y.; Yao, X.; Zhang, Y.; Li, W.; Kang, K.; Sun, L.; Sun, X. The protective role of hydrogen sulfide in myocardial ischemia-reperfusion-induced injury in diabetic rats. Int. J. Cardiol. 2011, 152, 177-183. [CrossRef] [PubMed]

33. Jha, S.; Calvert, J.W.; Duranski, M.R.; Ramachandran, A.; Lefer, D.J. Hydrogen sulfide attenuates hepatic ischemia-reperfusion injury: Role of antioxidant and antiapoptotic signaling. Am. J. Physiol. Heart Circ. Physiol. 2008, 295, H801-H806. [CrossRef] [PubMed]

34. Hunter, J.P.; Hosgood, S.A.; Patel, M.; Rose, R.; Read, K.; Nicholson, M.L. Effects of hydrogen sulphide in an experimental model of renal ischaemia-reperfusion injury. Br. J. Surg. 2012, 99, 1665-1671. [CrossRef] [PubMed]

35. Marutani, E.; Kosugi, S.; Tokuda, K.; Khatri, A.; Nguyen, R.; Atochin, D.N.; Kida, K.; Van Leyen, K.; Arai, K.; Ichinose, F. A novel hydrogen sulfide-releasing N-methyl-D-aspartate receptor antagonist prevents ischemic neuronal death. J. Biol. Chem. 2012, 287, 32124-32135. [CrossRef] [PubMed]

36. Wang, X.; Wang, L.; Sheng, X.; Huang, Z.; Li, T.; Zhang, M.; Xu, J.; Ji, H.; Yin, J.; Zhang, Y. Design, synthesis and biological evaluation of hydrogen sulfide releasing derivatives of 3-n-butylphthalide as potential antiplatelet and antithrombotic agents. Org. Biomol. Chem. 2014, 12, 5995-6004. [CrossRef] [PubMed]

37. Zhou, X.; Cao, Y.; Ao, G.; Hu, L.; Liu, H.; Wu, J.; Wang, X.; Jin, M.; Zheng, S.; Zhen, X.; et al. CaMKKbetadependent activation of AMP-activated protein kinase is critical to suppressive effects of hydrogen sulfide on neuroinflammation. Antioxid. Redox Signal. 2014, 21, 1741-1758. [CrossRef] [PubMed]

38. Wang, Y.L.; Jia, J.; Ao, G.Z.; Hu, L.F.; Liu, H.; Xiao, Y.Q.; Du, H.P.; Alkayed, N.J.; Liu, C.F.; Cheng, J. Hydrogen sulfide protects blood-brain barrier integrity following cerebral ischemia. J. Neurochem. 2014, 129, 827-838. [CrossRef] [PubMed]

39. Lee, M.; McGeer, E.; Kodela, R.; Kashfi, K.; McGeer, P.L. NOSH-aspirin (NBS-1120), a novel nitric oxide and hydrogen sulfide releasing hybrid, attenuates neuroinflammation induced by microglial and astrocytic activation: A new candidate for treatment of neurodegenerative disorders. Glia 2013, 61, 1724-1734. [CrossRef] [PubMed]

40. Zhang, Q.; Yuan, L.; Liu, D.X.; Wang, J.M.; Wang, S.L.; Zhang, Q.R.; Gong, Y.F.; Liu, H.D.; Hao, A.J.; Wang, Z. Hydrogen sulfide attenuates hypoxia-induced neurotoxicity through inhibiting microglial activation. Pharmacol. Res. 2014, 84, 32-44. [CrossRef] [PubMed] 
41. Lee, M.; McGeer, E.G.; McGeer, P.L. Sodium thiosulfate attenuates glial-mediated neuroinflammation in degenerative neurological diseases. J. Neuroinflamm. 2016, 13, 32. [CrossRef] [PubMed]

42. Yin, J.; Tu, C.; Zhao, J.; Ou, D.M.; Chen, G.W.; Liu, Y.; Xiao, X.Z. Exogenous hydrogen sulfide protects against global cerebral ischemia/reperfusion injury via its anti-oxidative, anti-inflammatory and anti-apoptotic effects in rats. Brain Res. 2013, 1491, 188-196. [CrossRef] [PubMed]

43. Hu, L.F.; Lu, M.; Tiong, C.X.; Dawe, G.S.; Hu, G.; Bian, J.S. Neuroprotective effects of hydrogen sulfide on Parkinson's disease rat models. Aging Cell 2010, 9, 135-146. [CrossRef] [PubMed]

44. Lee, H.J.; Lee, D.Y.; Mariappan, M.M.; Feliers, D.; Ghosh-Choudhury, G.; Abboud, H.E.; Gorin, Y.; Kasinath, B.S. Hydrogen sulfide inhibits high glucose-induced NADPH oxidase 4 expression and matrix increase by recruiting inducible nitric oxide synthase in kidney proximal tubular epithelial cells. J. Biol. Chem. 2017, 292, 5665-5675. [CrossRef] [PubMed]

45. Ma, M.W.; Wang, J.; Zhang, Q.; Wang, R.; Dhandapani, K.M.; Vadlamudi, R.K.; Brann, D.W. NADPH oxidase in brain injury and neurodegenerative disorders. Mol. Neurodegener. 2017, 12, 7. [CrossRef] [PubMed]

46. Manning, B.D.; Cantley, L.C. AKT/PKB signaling: Navigating downstream. Cell 2007, 129, 1261-1274. [CrossRef] [PubMed]

47. Brennan-Minnella, A.M.; Shen, Y.; El-Benna, J.; Swanson, R.A. Phosphoinositide 3-kinase couples NMDA receptors to superoxide release in excitotoxic neuronal death. Cell Death Dis. 2013, 4, e580. [CrossRef] [PubMed]

48. Szabo, C. Hydrogen sulphide and its therapeutic potential. Nat. Rev. Drug Discov. 2007, 6, 917-935. [CrossRef] [PubMed]

49. Xie, Z.Z.; Shi, M.M.; Xie, L.; Wu, Z.Y.; Li, G.; Hua, F.; Bian, J.S. Sulfhydration of p66Shc at Cysteine59 Mediates the Antioxidant Effect of Hydrogen Sulfide. Antioxid. Redox Signal. 2014, 21, 2531-2542. [CrossRef] [PubMed]

50. Yao, L.L.; Huang, X.W.; Wang, Y.G.; Cao, Y.X.; Zhang, C.C.; Zhu, Y.C. Hydrogen sulfide protects cardiomyocytes from hypoxia/reoxygenation-induced apoptosis by preventing GSK-3 beta-dependent opening of mPTP. Am. J. Physiol. Heart C 2010, 298, H1310-H1319. [CrossRef] [PubMed]

51. Coletta, C.; Papapetropoulos, A.; Erdelyi, K.; Olah, G.; Modis, K.; Panopoulos, P.; Asimakopoulou, A.; Gero, D.; Sharina, I.; Martin, E.; et al. Hydrogen sulfide and nitric oxide are mutually dependent in the regulation of angiogenesis and endothelium-dependent vasorelaxation. Proc. Natl. Acad. Sci. USA 2012, 109, 9161-9166. [CrossRef] [PubMed]

52. Zhao, Y.; Biggs, T.D.; Xian, M. Hydrogen sulfide (H2S) releasing agents: Chemistry and biological applications. Chem. Commun. 2014, 50, 11788-11805. [CrossRef] [PubMed]

53. Whiteman, M.; Li, L.; Rose, P.; Tan, C.H.; Parkinson, D.B.; Moore, P.K. The effect of hydrogen sulfide donors on lipopolysaccharide-induced formation of inflammatory mediators in macrophages. Antioxid. Redox Signal. 2010, 12, 1147-1154. [CrossRef] [PubMed]

54. Qu, K.; Chen, C.P.L.H.; Halliwell, B.; Moore, P.K.; Wong, P.T.H. Hydrogen sulfide is a mediator of cerebral ischemic damage. Stroke 2006, 37, 889-893. [CrossRef] [PubMed]

55. Kashfi, K.; Olson, K.R. Biology and therapeutic potential of hydrogen sulfide and hydrogen sulfide-releasing chimeras. Biochem. Pharmacol. 2013, 85, 689-703. [CrossRef] [PubMed]

56. Lee, M.; Tazzari, V.; Giustarini, D.; Rossi, R.; Sparatore, A.; Del Soldato, P.; McGeer, E.; McGeer, P.L. Effects of hydrogen sulfide-releasing L-DOPA derivatives on glial activation: Potential for treating Parkinson disease. J. Biol. Chem. 2010, 285, 17318-17328. [CrossRef] [PubMed]

57. Liu, Y.Y.; Sparatore, A.; Del Soldato, P.; Bian, J.S. ACS84, a novel hydrogen sulfide-releasing compound, protects against amyloid beta-induced cell cytotoxicity. Neurochem. Int. 2011, 58, 591-598. [CrossRef] [PubMed]

58. Bachour, S.P.; Hevesi, M.; Bachour, O.; Sweis, B.M.; Mahmoudi, J.; Brekke, J.A.; Divani, A.A. Comparisons between Garcia, Modo, and Longa rodent stroke scales: Optimizing resource allocation in rat models of focal middle cerebral artery occlusion. J. Neurol. Sci. 2016, 364, 136-140. [CrossRef] [PubMed]

59. Zausinger, S.; Hungerhuber, E.; Baethmann, A.; Reulen, H.J.; Schmid-Elsaesser, R. Neurological impairment in rats after transient middle cerebral artery occlusion: A comparative study under various treatment paradigms. Brain Res. 2000, 863, 94-105. [CrossRef] 
60. Weinstein, J.R.; Koerner, I.P.; Moller, T. Microglia in ischemic brain injury. Future Neurol. 2010, 5, $227-246$. [CrossRef] [PubMed]

61. Jin, R.; Yang, G.J.; Li, G.H. Inflammatory mechanisms in ischemic stroke: Role of inflammatory cells. J. Leukocyte Biol. 2010, 87, 779-789. [CrossRef] [PubMed]

62. Gelderblom, M.; Leypoldt, F.; Steinbach, K.; Behrens, D.; Choe, C.U.; Siler, D.A.; Arumugam, T.V.; Orthey, E.; Gerloff, C.; Tolosa, E.; et al. Temporal and spatial dynamics of cerebral immune cell accumulation in stroke. Stroke 2009, 40, 1849-1857. [CrossRef] [PubMed]

63. Schilling, M.; Strecker, J.K.; Schabitz, W.R.; Ringelstein, E.B.; Kiefer, R. Effects of monocyte chemoattractant protein 1 on blood-borne cell recruitment after transient focal cerebral ischemia in mice. Neuroscience 2009, 161, 806-812. [CrossRef] [PubMed]

64. Schilling, M.; Besselmann, M.; Leonhard, C.; Mueller, M.; Ringelstein, E.B.; Kiefer, R. Microglial activation precedes and predominates over macrophage infiltration in transient focal cerebral ischemia: A study in green fluorescent protein transgenic bone marrow chimeric mice. Exp. Neurol. 2003, 183, 25-33. [CrossRef]

65. Schilling, M.; Besselmann, M.; Muller, M.; Strecker, J.K.; Ringelstein, E.B.; Kiefer, R. Predominant phagocytic activity of resident microglia over hematogenous macrophages following transient focal cerebral ischemia: An investigation using green fluorescent protein transgenic bone marrow chimeric mice. Exp. Neurol. 2005, 196, 290-297. [CrossRef] [PubMed]

66. Weston, R.M.; Jones, N.M.; Jarrott, B.; Callaway, J.K. Inflammatory cell infiltration after endothelin-1-induced cerebral ischemia: Histochemical and myeloperoxidase correlation with temporal changes in brain injury. J. Cereb. Blood Flow Metab. 2007, 27, 100-114. [CrossRef] [PubMed]

67. Wu, D.D.; Li, M.L.; Tian, W.K.; Wang, S.W.; Cui, L.Z.; Li, H.; Wang, H.J.; Ji, A.L.; Li, Y.Z. Hydrogen sulfide acts as a double-edged sword in human hepatocellular carcinoma cells through EGFR/ERK/MMP-2 and PTEN/AKT signaling pathways. Sci. Rep. 2017, 7, 5134. [CrossRef] [PubMed]

68. Cobb, C.A.; Cole, M.P. Oxidative and nitrative stress in neurodegeneration. Neurobiol. Dis. 2015, 84, 4-21. [CrossRef] [PubMed]

69. Andersen, J.K. Oxidative stress in neurodegeneration: Cause or consequence? Nat. Med. 2004, 10, S18-S25. [CrossRef] [PubMed]

70. Kahles, T.; Brandes, R.P. Which NADPH Oxidase Isoform Is Relevant for Ischemic Stroke? The Case for Nox 2. Antioxid. Redox Signal. 2013, 18, 1400-1417. [CrossRef] [PubMed]

71. Carbone, F.; Teixeira, P.C.; Braunersreuther, V.; Mach, F.; Vuilleumier, N.; Montecucco, F. Pathophysiology and Treatments of Oxidative Injury in Ischemic Stroke: Focus on the Phagocytic NADPH Oxidase 2. Antioxid. Redox Signal. 2015, 23, 460-489. [CrossRef] [PubMed]

72. Green, S.P.; Cairns, B.; Rae, J.; Errett-Baroncini, C.; Hongo, J.A.S.; Erickson, R.W.; Curnutte, J.T. Induction of gp91-phox, a component of the phagocyte NADPH oxidase, in microglial cells during central nervous system inflammation. J. Cereb. Blood Flow Metab. 2001, 21, 374-384. [CrossRef] [PubMed]

73. Wang, X.L.; Wang, L.N.; Li, T.T.; Huang, Z.J.; Lai, Y.S.; Ji, H.; Wan, X.L.; Xu, J.Y.; Tian, J.D.; Zhang, Y.H. Novel Hybrids of Optically Active Ring-Opened 3-n-Butylphthalide Derivative and Isosorbide as Potential Anti-Ischemic Stroke Agents. J. Med. Chem. 2013, 56, 3078-3089. [CrossRef] [PubMed]

74. Li, C.H.; Wang, J.; Fang, Y.Q.; Liu, Y.; Chen, T.; Sun, H.; Zhou, X.F.; Liao, H. Nafamostat mesilate improves function recovery after stroke by inhibiting neuroinflammation in rats. Brain Behav. Immun. 2016, 56, 230-245. [CrossRef] [PubMed]

75. Longa, E.Z.; Weinstein, P.R.; Carlson, S.; Cummins, R. Reversible middle cerebral artery occlusion without craniectomy in rats. Stroke 1989, 20, 84-91. [CrossRef] [PubMed]

76. Biernaskie, J.; Chernenko, G.; Corbett, D. Efficacy of rehabilitative experience declines with time after focal ischemic brain injury. J. Neurosci. 2004, 24, 1245-1254. [CrossRef] [PubMed]

77. Hara, H.; Huang, P.L.; Panahian, N.; Fishman, M.C.; Moskowitz, M.A. Reduced brain edema and infarction volume in mice lacking the neuronal isoform of nitric oxide synthase after transient MCA occlusion. J. Cereb. Blood Flow Metab. 1996, 16, 605-611. [CrossRef] [PubMed]

78. Kaushal, V.; Schlichter, L.C. Mechanisms of microglia-mediated neurotoxicity in a new model of the stroke penumbra. J. Neurosci. 2008, 28, 2221-2230. [CrossRef] [PubMed]

79. Jung, K.H.; Chu, K.; Lee, S.T.; Kim, S.J.; Song, E.C.; Kim, E.H.; Park, D.K.; Sinn, D.I.; Kim, J.M.; Kim, M.; et al. Blockade of AT1 receptor reduces apoptosis, inflammation, and oxidative stress in normotensive rats with intracerebral Hemorrhage. J. Pharmacol. Exp. Ther. 2007, 322, 1051-1058. [CrossRef] [PubMed] 
80. Liu, T.; Zhang, T.; Yu, H.; Shen, H.; Xia, W. Adjudin protects against cerebral ischemia reperfusion injury by inhibition of neuroinflammation and blood-brain barrier disruption. J. Neuroinflamm. 2014, 11, 107. [CrossRef] [PubMed]

81. Ji, J.; Xiang, P.; Li, T.; Lan, L.; Xu, X.; Lu, G.; Ji, H.; Zhang, Y.; Li, Y. NOSH-NBP, a Novel Nitric Oxide and Hydrogen Sulfide- Releasing Hybrid, Attenuates Ischemic Stroke-Induced Neuroinflammatory Injury by Modulating Microglia Polarization. Front. Cell. Neurosci. 2017, 11, 154. [CrossRef] [PubMed]

Sample Availability: Samples of the compound $8 \mathbf{e}$ is not available from the authors.

(C) 2018 by the authors. Licensee MDPI, Basel, Switzerland. This article is an open access article distributed under the terms and conditions of the Creative Commons Attribution (CC BY) license (http://creativecommons.org/licenses/by/4.0/). 